\title{
Process intensification in the catalytic conversion of natural gas to fuels and chemicals
}

\author{
Robert J. Kee ${ }^{\mathrm{a}, *}$, Canan Karakaya ${ }^{\mathrm{a}}$, Huayang Zhu ${ }^{\mathrm{a}}$ \\ a Department of Mechanical Engineering, Colorado School of Mines, Golden, CO 80401, USA
}

\begin{abstract}
This paper explores alternative technologies for the conversion of natural gas to higher-value products. Because of methane's chemical stability, all practical processes require elevated temperature (e.g., $T>700{ }^{\circ} \mathrm{C}$ ) and catalysts to activate the methane. Some approaches are mature and widely practiced at the commercial scale (e.g., steam reforming and Fischer-Tropsch synthesis). Others are emerging, based on laboratory-scale experimentation (e.g., oxidative coupling of methane). In all cases, the present paper is concerned with aspects of process intensification, seeking chemical methods and reactor implementations that can improve overall performance. Performance metrics include reactor size, energy efficiency, conversion rates, and product selectivity. Process intensification approaches include integrated microchannel reactors and heat exchangers as well as a range of permselective membranes.
\end{abstract}

Keywords:

Gas-to-liquids, Catalysis, Methane reforming, Fischer-Tropsch, Oxidative coupling of methane, Process

intensification, Membrane reactors, Microchannel reactors

\section{Introduction}

In today's energy marketplace, natural gas is, and is projected to be, plentiful and inexpensive. Because of its relatively low carbon footprint, gas will surely play increasingly prominent roles in combustion. Ongoing research will likely lead to more efficient and environmentally friendly combustion processes. At the same time, natural gas is likely to be an increasingly important feedstock for the production of logistics fuels and commodity chemicals. The primary objective of this paper is to consider processes that can effectively transform natural gas into other higher-value hydrocarbons. This topic is the subject of much current interest and research [1-10].

Converting natural gas to liquids (GTL) is certainly not new. Broadly speaking, two routes have been scaled to commercial levels. One is Fischer-Tropsch [11] the other is methanol synthesis [12]. In both cases, the methane is first reformed to synthesis gas (i.e., $\mathrm{H}_{2}$ and $\mathrm{CO})$. However, if a hydrocarbon product is desired, the

${ }^{*}$ Corresponding author. Tel: +1-303-273-3779; Fax:+1-303-2733602 .

Email address: rjkee@mines . edu (Robert J. Kee)

Preprint submitted to Proc. Combust. Inst. initial oxidation to syngas represents an inherent inefficiency. Thus, there is at least the potential to develop more efficient and direct dehydrogenation processes. Processes such as oxidative coupling of methane (OCM) show promise, but have yet to achieve commercial viability.

All practical GTL processes require elevated temperature (e.g., $T>700{ }^{\circ} \mathrm{C}$ ) and product-selective catalysts. Innovative research is leading to new catalyst materials and microstructures (e.g., nanorods or nanofibers) that improve performance. There is general agreement that "process intensification" concepts will contribute to the development of new processing approaches and reactor technologies. This paper is concerned mostly with opportunities for novel process and reactor concepts, especially considering the beneficial close coupling of chemical and thermal interactions.

\subsection{Economic considerations}

Natural gas will surely continue to have major impacts on the production of energy and chemicals. However, because of highly volatile markets and prices for natural gas and oil, planning the best uses for the gas is difficult. Figure 1 shows the history of gas and oil prices for the past ten years. There are periods where

May 22, 2016 


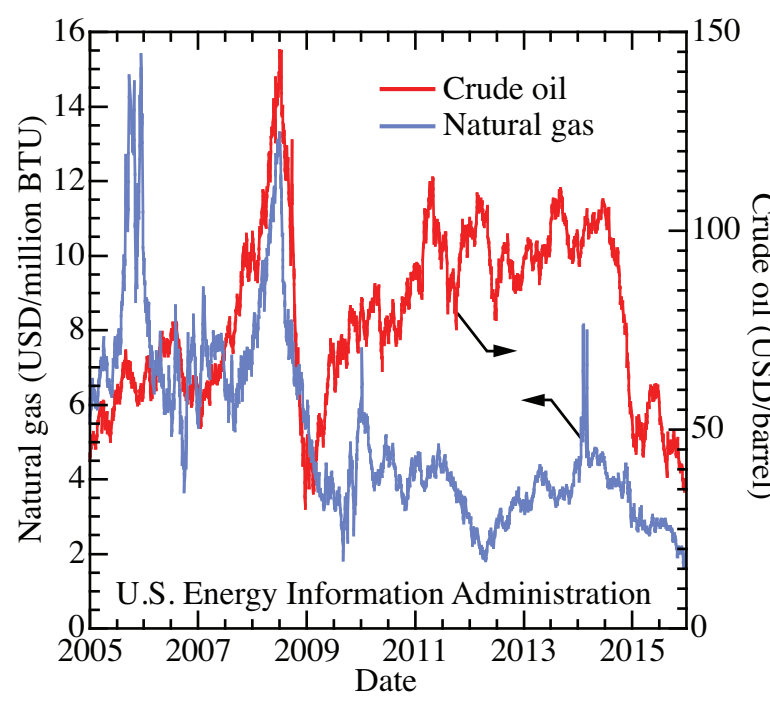

Figure 1: Comparison of oil and gas prices from 2005 through 2015. The historical data was downloaded from the U.S. Energy Information Agency (http://www.eia.gov).

the prices appear to be correlated, rising and falling together. There are periods where the gas price is relatively high while the oil price is low, and there are periods with just the opposite relationship. As of the present writing (early 2016), both oil and gas prices are at historic lows, but gas prices appear to be rising while oil prices are not.

Maitlis and de Klerk describe the impact of market volatility in terms of the "haitus effect" [13, 14]. Developing new, clean, sustainable processes requires longterm (order of 20 years or more) research and development. However, investment decisions, and thus research ${ }^{105}$ support, are often made on much shorter timescales. A ${ }^{106}$ consequence, for example, is that in periods of rela- ${ }^{107}$ tively low oil prices, interest in converting gas to fuels 108 wanes and investment is low. During such periods, re- 109 search loses momentum and knowledgeable people fol- 110 low other pursuits. As periods of relatively high oil 111 prices return, restarting the research and development ${ }^{112}$ can be slow and inefficient. In the long term, it is reason- ${ }^{113}$ ably clear that natural gas will continue to play a central ${ }^{114}$ role in the production of logistics fuels and commod- ${ }^{115}$ ity chemicals. Thus, finding ways to sustain long-range 116 research and development is likely to deliver societal, ${ }^{117}$ environmental, and economic benefits.

\subsection{Combustion perspective}

This paper is written in the context of a plenary lecture for the 36th International Symposium on Combus- 120 tion (Seoul, Korea, July 2016). Of course, the Com- ${ }_{121}$ bustion Community is concerned primarily with the efficient and complete oxidation of fuels, not the synthesis or transformation of fuels. Nevertheless, with sustained research in hydrocarbon chemistry over the past half century, this community has developed core capabilities that can play valuable roles in the alternative uses of fossil fuels, especially natural gas. Thus, there are interesting opportunities to build on the strong foundation of combustion research.

A quick electronic search of the program for the 35 th International Symposium on Combustion reveals 471 occurrences of "methane," 155 occurrences of "syngas," and 166 occurrences of "catalysis." At the 26th Symposium (1996), a colloquium was introduced on "Materials Synthesis and Catalytic Combustion." A new colloquium on "New Concepts in Combustion Technology" was introduced at the 29th Symposium (2002). Beginning at the 30th Symposium (2004), there began to be discussion of solid-oxide fuel cells (SOFC) with hydrocarbon fuels [15]. Although fuel cells consume fuels to produce electricity and heat, they also involve new concepts in electrochemistry, ion-transport membranes, in-situ catalytic reforming, and small-channel reactive flow. All of these topics are relevant for advanced processes to transform natural gas and synthesize fuels and chemicals. At the same time, understanding and appreciating aspects of the process-intensification concepts that are proving to be valuable in the chemical processing context may be adaptable to advanced combustion technologies.

\subsection{Natural gas and methane}

Although methane is its dominant component, it is well known that natural gas is a mixture of small hydrocarbons and usually impurities such as sulfur compounds. In combustion processes, these non-methane components are often negligible for many purposes. However, in catalytic processes, the non-methane components can play much larger roles. The present paper does focus on methane, especially in the context of discussing process chemistry. Also, as is evident from the cited literature, much laboratory-scale research dose focus on methane as a natural-gas surrogate. Nevertheless, practical technology development needs to be cognizant of the variable composition and added complexities associated with natural gas.

\section{Methane reforming}

Alternative forms of synthesis gas (i.e., mixtures of $\mathrm{H}_{2}$ and $\mathrm{CO}$ ) play foundational roles in the production of 
chemicals (e.g., olefins, ethers, ammonia, alcohols) and ${ }_{159}$ synthetic logistics fuels (e.g., via Fischer-Tropsch pro- 160 cesses). As measured in the megawatt thermal equiv- 161 alent, the current annual syngas production exceeds ${ }_{162}$ 100,000 MWth and is estimated to double in the next ${ }_{163}$ five years.

Reforming to produce synthesis gas plays a central 165 role in large-scale hydrogen production for a variety of 166 purposes, including the upgrading of petroleum-derived 167 fuels. As documented by Rostrup-Nielsen and col- 168 leagues $[16,5]$, catalytic steam reforming has been the 169 subject of research since the early 1900s. However, it 170 was not until the 1960s that large-scale, high-pressure, 171 tubular steam reformers were used industrially. Prior 172 to the the development of methane reforming processes, 173 hydrogen was produced by cracking petroleum-derived 174 naphtha. ${ }^{1}$

As is well known and widely practiced, catalytic 176 methane reforming can be accomplished by one of three 177 processes, or a combination of processes. Stated globally, endothermic steam reforming (SMR) can be expressed as

$$
\mathrm{CH}_{4}+\mathrm{H}_{2} \mathrm{O} \rightleftarrows 3 \mathrm{H}_{2}+\mathrm{CO}, \quad \Delta H_{298}^{\circ} \approx 206 \mathrm{~kJ} \mathrm{~mol}^{-1} .
$$

Dry reforming (DRM) can be expressed as

$$
\mathrm{CH}_{4}+\mathrm{CO}_{2} \rightleftarrows 2 \mathrm{H}_{2}+2 \mathrm{CO}, \quad \Delta H_{298}^{\circ} \approx 247 \mathrm{~kJ} \mathrm{~mol}^{-1} \text {. }
$$

Both SRM and DRM are strongly endothermic. Catalytic partial oxidation (CPOX), which is exothermic, can be represented globally as

$$
\mathrm{CH}_{4}+\frac{1}{2} \mathrm{O}_{2} \rightleftarrows 2 \mathrm{H}_{2}+\mathrm{CO}, \quad \Delta H_{298}^{\circ} \approx-38 \mathrm{~kJ} \mathrm{~mol}^{-1} \text {. }
$$

A thermally neutral combination of the three processes ${ }^{187}$ is known as autothermal reforming (ATR). All these processes operate at elevated temperature $\left(T>700^{\circ} \mathrm{C}\right)$ and catalysts are needed. Ni-based catalysts are typical ${ }_{188}$ for SMR and precious-metal catalysts (e.g., Rh) are typ- 189 ical for CPOX. Especially in the case of SMR, a large 190 excesses of $\mathrm{H}_{2} \mathrm{O}$ is used to mitigate catalyst-fouling carbon deposits.

\section{1. $\mathrm{CO}-\mathrm{H}_{2}$ ratio}

Although the alternative methane reforming routes 195 can all achieve high $\mathrm{CH}_{4}$ conversion and syngas yield, ${ }_{190}$

${ }^{1}$ Heavy naphtha is a mixture of petroleum distillates composed of paraffins, aromatics, and naphthenes in the range of $\mathrm{C}_{6}$ to $\mathrm{C}_{12}$. Light naphthas $\left(C_{5}\right.$ and $\left.C_{6}\right)$ were used directly for blending into gasoline 200 and related products. the resulting syngas compositions are different. Depending on the intended use for the syngas, the $\mathrm{H}_{2} / \mathrm{CO}$ ratio is very important.

Steam reforming (Eq. 1) produces a $\mathrm{H}_{2}$-rich gas stream together with relatively low levels of CO. Because steam reformation is often intended to produce high-purity $\mathrm{H}_{2}$, the reformer itself is typically followed by downstream water-gas-shift (CO $+\mathrm{H}_{2} \mathrm{O} \rightleftharpoons \mathrm{H}_{2}+\mathrm{CO}_{2}$, WGS) reactors to convert $\mathrm{CO}$ to $\mathrm{CO}_{2}$ and $\mathrm{H}_{2}$. The $\mathrm{H}_{2}$ is usually purified further, such as with pressure-swing-adsorption (PSA). Pure $\mathrm{H}_{2}$ is a valuable commodity that can be used for ammonia synthesis, petroleum refining, or in fuel-cell applications. Worldwide, approximately 50 metric tonnes of $\mathrm{H}_{2}$ are produced and consumed annually.

Dry reforming (Eq. 2) yields a $\mathrm{H}_{2} / \mathrm{CO}$ ratio of unity, which is an ideal stoichiometry for applications such as the production of acetic acid, which may be represented globally as

$$
2 \mathrm{CO}+2 \mathrm{H}_{2} \rightleftharpoons \mathrm{CH}_{3} \mathrm{COOH} .
$$

Partial oxidation (Eq. 3) yields a $\mathrm{H}_{2} / \mathrm{CO}$ ratio of two, which is the ideal ratio for methanol synthesis or FisherTropsch processes. Methanol synthesis can be represented globally as

$$
\mathrm{CO}+2 \mathrm{H}_{2} \rightleftharpoons \mathrm{CH}_{3} \mathrm{OH} .
$$

The Fisher-Tropsch process can be written globally as

$$
n \mathrm{CO}+2 n \mathrm{H}_{2} \rightleftharpoons\left(-\mathrm{CH}_{2}-\right)_{n}+n \mathrm{H}_{2} \mathrm{O},
$$

where $\left(-\mathrm{CH}_{2}-\right)_{n}$ indicates a large alkane.

The syngas composition (i.e., $\mathrm{H}_{2} / \mathrm{CO}$ ratio) can be adjusted by combining steam reforming and dry reforming. Written globally, the combined processes may be represented as

$$
\mathrm{CH}_{4}+x \mathrm{H}_{2} \mathrm{O}+(1-x) \mathrm{CO}_{2} \rightleftharpoons(2-x) \mathrm{CO}+(2+x) \mathrm{H}_{2},
$$

where $x$ represents the amounts of $\mathrm{H}_{2} \mathrm{O}$ and $\mathrm{CO}_{2}$ in the feed stream. Dry reforming and combined dry and steam reforming have some appeal in the context of capturing and reusing the carbon in $\mathrm{CO}_{2}$. Although this may offer some environmental benefits, the production of $\mathrm{CO}_{2}$ from fossil-fuel power plants massively exceeds the need for $\mathrm{CO}_{2}$ in reforming processes. Thus, the primary reason to use $\mathrm{CO}_{2}$ in reformation processes is to control the $\mathrm{CO}-\mathrm{H}_{2}$ content in the syngas. Nevertheless, there are certainly benefits to designing and locating reformers that can take advantage of available $\mathrm{CO}_{2}$.

Because both steam and dry reforming processes operate at high temperature, a great deal of energy is required to support the reforming endotherm. The needed 
energy is typically generated by burning a substantial fraction of the natural gas, representing a significant process inefficiency. Thus, attention to overall thermal management in the design and operation of reformers is very important. One approach is to develop recuperators that use hot post-combustion flue gases as efficiently as possible. Another approach is to combine or closely couple exothermic partial-oxidation processes with endothermic reforming. The combination of steam reforming and partial oxidation can be represented globally as

$$
\begin{array}{r}
\mathrm{CH}_{4}+(1-x) \mathrm{H}_{2} \mathrm{O}+\frac{x}{2} \mathrm{O}_{2} \rightleftharpoons \mathrm{CO}+(3-x) \mathrm{H}_{2} \\
\Delta H_{298}^{\circ}=206.2-241.8 x \mathrm{~kJ} \mathrm{~mol}^{-1} .
\end{array}
$$

Although autothermal reforming can assist with thermal balances, there are other important, and often competing, considerations. One is the resulting syngas composition, which is influenced by the intended downstream use of the syngas. Another is the need for pure oxygen. Air separation, which is usually accomplished upstream of the reformer, is also energy intensive. As discussed subsequently, there are significant opportunities for process intensification in the combination of reforming and partial-oxidation processes.

\subsection{Process tradeoffs}

Reformer operational parameters include feed com- ${ }^{252}$ position, temperature, and pressure. In consideration ${ }^{253}$ of high-pressure downstream processes (e.g., Fischer- ${ }^{254}$ Tropsch synthesis), industrial-scale reformers typically 255 operate at elevated pressure $(20 \leq p \leq 40$ bar $)$. Post-reformer syngas compression is expensive [17]. ${ }^{256}$ The high-temperature durability of stainless steel reac- ${ }^{257}$ tor materials typically limits the operating pressure to 258 around 40 bar [18].

From the chemistry perspective (i.e., Le Châtelier's 260 principle), neither $\mathrm{H}_{2} \mathrm{O}$ nor $\mathrm{CO}_{2}$ reforming or partial ox- ${ }_{261}$ idation processes are favored at high pressure. Figure 2a 262 shows that increasing pressure from 1 bar to 25 bar de- 263 creases the $\mathrm{CH}_{4}$ conversion significantly. The figure 264 also shows that increasing temperature always increases 265 conversion. However, at elevated pressure the tempera- 266 ture needs to be in the range of $900 \leq T \leq 1000^{\circ} \mathrm{C}$ to ${ }_{267}$ achieve significant $\mathrm{CH}_{4}$ conversion. As shown in Fig- 268 ure $2 \mathrm{~b}$, another way to increase the $\mathrm{CH}_{4}$ conversion at 269 high pressure is to operate with excess $\mathrm{H}_{2} \mathrm{O}$. With ex- 270 cess $\mathrm{H}_{2} \mathrm{O}$, water-gas-shift processes act to convert $\mathrm{CO}$ to 271 $\mathrm{H}_{2}$. As a result, $\mathrm{H}_{2}$ selectivity increases while $\mathrm{CO}$ selec- 272 tivity decreases. However, the excess $\mathrm{H}_{2} \mathrm{O}$ reduces the ${ }_{273}$ methane concentration, thus reducing the syngas pro- 274 duction rates.
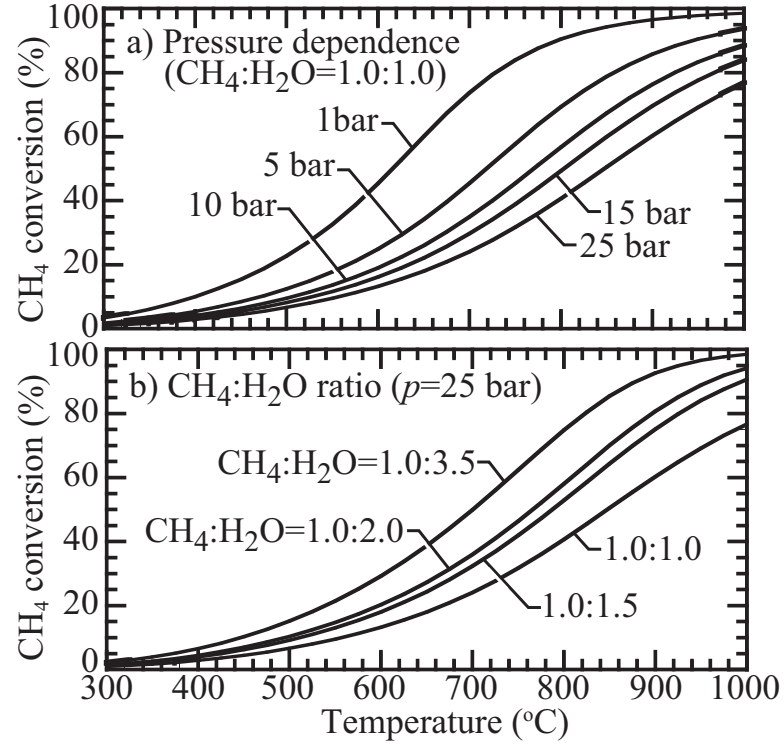

Figure 2: Influence of temperature, pressure, and feed composition on the equilibrium methane conversion in steam reforming processes. a) Effect of pressure with $\mathrm{CH}_{4} / \mathrm{H}_{2} \mathrm{O}=1$. b) Effect of $\mathrm{CH}_{4} / \mathrm{H}_{2} \mathrm{O}$ ratio at $p=25$ bar

With respect to pressure and temperature dependencies, partial oxidation behaves similarly to the steam reforming chemistry. That is, increasing pressure decreases both methane conversion and $\mathrm{H}_{2}$ and $\mathrm{CO}$ selectivity. Increasing $\mathrm{O}_{2}$ in the feed increases methane conversion toward the unwanted total oxidation products [19].

\subsection{Reforming catalysts}

Catalyst performance (i.e., reaction rates, methane conversion, product selectivity and yield) greatly influences reactor design and operating conditions. A number of transition metals, including $\mathrm{Rh}, \mathrm{Ni}, \mathrm{Ir}, \mathrm{Ru}, \mathrm{Pt}$ and Co, are known to be active as methane reforming catalysts [3]. The active metals are usually dispersed as small (nanoscale) particles that are supported on porous-ceramic supports, such as $\mathrm{Al}_{2} \mathrm{O}_{3}$. Among these transition metals, $\mathrm{Rh}$ and $\mathrm{Ru}$ are known to be the most active active and stable. However, at the industrial scale, Ni is usually preferred because of its lower cost. Unfortunately, $\mathrm{Ni}$ also has the highest potential to form catalyst-deactivating coke and carbon deposits [5]. The coking propensity is greatest for $\mathrm{Ni}$, with the coking propensity of the other metals being ordered as $\mathrm{Ni} \geq$ $\mathrm{Pd} \gg \mathrm{Ir} \geq \mathrm{Pt} \geq \mathrm{Ru} \approx \mathrm{Rh}$.

Transition metals and mixtures (e.g., Rh-Pd, Rh-Pt) on oxide supports are also used for methane partial oxidation. Although Ni can be used for CPOX, its rela- 
Table 1: Heterogeneous reaction mechanism for $\mathrm{CH}_{4}$ reforming on a ${ }^{306}$ Ni-based catalyst [24, 25, 32]. The phases are noted in parentheses, ${ }^{307}$ with $(\mathrm{g})$ representing the gas and $(\mathrm{Ni})$ representing the nickel surface. 308 $\mathrm{H}_{2}(\mathrm{~g})+2(\mathrm{Ni}) \leftrightharpoons \mathrm{H}(\mathrm{Ni})+\mathrm{H}(\mathrm{Ni})$

$\mathrm{O}_{2}(\mathrm{~g})+(\mathrm{Ni})+(\mathrm{Ni}) \leftrightharpoons \mathrm{O}(\mathrm{Ni})+\mathrm{O}(\mathrm{Ni})$

$\mathrm{CH}_{4}(\mathrm{~g})+(\mathrm{Ni}) \leftrightharpoons \mathrm{CH}_{4}(\mathrm{Ni})$

$\mathrm{H}_{2} \mathrm{O}(\mathrm{g})+(\mathrm{Ni}) \leftrightharpoons \mathrm{H}_{2} \mathrm{O}(\mathrm{Ni})$

$\mathrm{CO}_{2}(\mathrm{~g})+(\mathrm{Ni}) \leftrightharpoons \mathrm{CO}_{2}(\mathrm{Ni})$

$\mathrm{CO}(\mathrm{g})+(\mathrm{Ni}) \leftrightharpoons \mathrm{CO}(\mathrm{Ni})$

$\mathrm{O}(\mathrm{Ni})+\mathrm{H}(\mathrm{Ni}) \leftrightharpoons \mathrm{OH}(\mathrm{Ni})+(\mathrm{Ni})$

$\mathrm{OH}(\mathrm{Ni})+\mathrm{H}(\mathrm{Ni}) \leftrightharpoons \mathrm{H}_{2} \mathrm{O}(\mathrm{Ni})+(\mathrm{Ni})$

$\mathrm{OH}(\mathrm{Ni})+\mathrm{OH}(\mathrm{Ni}) \leftrightharpoons \mathrm{O}(\mathrm{Ni})+\mathrm{H}_{2} \mathrm{O}(\mathrm{Ni})$

$\mathrm{O}(\mathrm{Ni})+\mathrm{C}(\mathrm{Ni}) \leftrightharpoons \mathrm{CO}(\mathrm{Ni})+(\mathrm{Ni})$

$\mathrm{O}(\mathrm{Ni})+\mathrm{CO}(\mathrm{Ni}) \leftrightharpoons \mathrm{CO}_{2}(\mathrm{Ni})+(\mathrm{Ni})$

$\mathrm{HCO}(\mathrm{Ni})+(\mathrm{Ni}) \leftrightharpoons \mathrm{CO}(\mathrm{Ni})+\mathrm{H}(\mathrm{Ni})$

$\mathrm{HCO}(\mathrm{Ni})+(\mathrm{Ni}) \leftrightharpoons \mathrm{O}(\mathrm{Ni})+\mathrm{CH}(\mathrm{Ni})$

$\mathrm{CH}_{4}(\mathrm{Ni})+(\mathrm{Ni}) \leftrightharpoons \mathrm{CH}_{3}(\mathrm{Ni})+\mathrm{H}(\mathrm{Ni})$

$\mathrm{CH}_{3}(\mathrm{Ni})+(\mathrm{Ni}) \leftrightharpoons \mathrm{CH}_{2}(\mathrm{Ni})+\mathrm{H}(\mathrm{Ni})$

$\mathrm{CH}_{2}(\mathrm{Ni})+(\mathrm{Ni}) \leftrightharpoons \mathrm{CH}(\mathrm{Ni})+\mathrm{H}(\mathrm{Ni})$

$\mathrm{CH}(\mathrm{Ni})+(\mathrm{Ni}) \leftrightharpoons \mathrm{C}(\mathrm{Ni})+\mathrm{H}(\mathrm{Ni})$

$\mathrm{O}(\mathrm{Ni})+\mathrm{CH}_{4}(\mathrm{Ni}) \leftrightharpoons \mathrm{CH}_{3}(\mathrm{Ni})+\mathrm{OH}(\mathrm{Ni})$

$\mathrm{O}(\mathrm{Ni})+\mathrm{CH}_{3}(\mathrm{Ni}) \leftrightharpoons \mathrm{CH}_{2}(\mathrm{Ni})+\mathrm{OH}(\mathrm{Ni})$

$\mathrm{O}(\mathrm{Ni})+\mathrm{CH}_{2}(\mathrm{Ni}) \leftrightharpoons \mathrm{CH}(\mathrm{Ni})+\mathrm{OH}(\mathrm{Ni})$

$\mathrm{O}(\mathrm{Ni})+\mathrm{CH}(\mathrm{Ni}) \leftrightharpoons \mathrm{C}(\mathrm{Ni})+\mathrm{OH}(\mathrm{Ni})$

tively lower activity requires temperatures in excess of $750{ }^{\circ} \mathrm{C}$. Unfortunately, at these temperatures $\mathrm{Ni}$ reacts with $\mathrm{Al}_{2} \mathrm{O}_{3}$ to form $\mathrm{NiAl}_{2} \mathrm{O}_{4}$, leading to rapid deactivation. Fresh catalysts can deliver high partial-oxidation activity that is close to equilibrium limits. However, similar to steam and dry reforming, coke formation can be a significant problem for CPOX processes. The coke propensity is ordered as $\mathrm{Ni}>\mathrm{Pd}>\mathrm{Rh}>\mathrm{Ru}>\mathrm{Pt} \approx$ $\operatorname{Ir}[19,20]$.

\subsection{Reforming kinetics}

The discussion to this point in the paper has considered only global reactions. Of course, the actual processes are far more complex, with quantitative predic- 340 tive understanding depending on detailed mechanisms ${ }_{341}$ composed of elementary reaction steps [21-31]. As an ${ }_{342}$ example, Table 1 lists a 21-step mechanism that repre- ${ }_{343}$ sents catalytic interactions of $\mathrm{CH}_{4}, \mathrm{H}_{2}, \mathrm{O}_{2}, \mathrm{H}_{2} \mathrm{O}, \mathrm{CO},{ }_{344}$ and $\mathrm{CO}_{2}$ on Ni surfaces [24, 25, 32].

Unlike global reactions that consider only gas-phase 346 species (e.g., global steam-reforming, Eq. 1), the de- 347 tailed mechanisms consider both gas-phase and surface- 348 adsorbed species. Detailed reaction mechanisms pro- 349 vide a much richer description of the chemistry than the 350 global reactions can, which has practical benefits. Note ${ }_{351}$ that global steam-reforming, dry reforming, partial oxi- ${ }_{352}$ dation, and water-gas-shift reactions, per se, do not ap- ${ }_{353}$ pear as individual reactions in the detailed mechanisms. ${ }_{354}$ The detailed mechanisms capture wide process ranges, 355 whereas a few global steps usually can not. In other 356 words, mechanisms such as the one in Table 1 represent ${ }_{357}$ the entire range of behaviors that span steam reforming, dry reforming, partial oxidation, and autothermal reforming. Although developing the elementary reaction pathways and rate expressions can be challenging, a validated elementary mechanism has very great value.

Despite the generality and practical success of detailed reaction mechanisms, there are important fundamental and practical challenges for future research. Available detailed reaction mechanisms for heterogeneous catalysis are generally restricted to applications such as methane reforming or oxidation. Even in these cases, extensions are needed. For example, although catalyst-fouling carbon deposition is a major practical issue, there is relatively little research devoted to incorporating carbon deposition into the detailed mechanisms. Feedstocks often contain sulfur compounds and sulfur can play a major role in catalyst performance. Thus, there are opportunities to extend detailed reaction mechanisms to account for sulfur [29]. Yet other examples include a wide range of process and chemical feedstocks. Detailed reaction mechanisms have not yet been developed for many industrially practiced processes. These include a range of traditional processes such as olefin production. The reaction pathways for processes such as Fischer-Tropsch synthesis or the oxidative coupling of methane (OCM) are understood qualitatively, However, detailed quantitative and predictive reaction mechanisms are generally not available.

Essentially all current reaction mechanisms are based on a mean-field approximation. That is, the surfaceadsorbate activities are assumed to be represented in terms of a average coverage fractions. In fact, it is known that adsorbates can cluster into islands on catalyst surfaces. To some extent this behavior can be approximated by using rate expressions with coveragedependent activation energies [33]. Relaxing the meanfield approximation in favor of better physical representations is difficult, but research in this direction would be highly valuable.

Although Table 1 represents the reactions as being microscopically reversible, most available reaction mechanisms represent the reactions as irreversible pairs. In this case, the microscopic reversibility is only approximately satisfied. Because most of the reactions involve surface-adsorbed species, the thermodynamic properties of those species are needed to establish equilibrium constants, and hence microscopic reversibility. The needed properties are difficult, or even impossible, to measure. In principle, ab-initio theory can be used to determine the needed thermodynamic properties [3436]. However, such properties are certainly not generally available. There is active research devoted to esti- 
mating the thermodynamic properties needed to assure microscopic reversibility [37, 38, 33, 39].

To date, research on detailed reaction mechanisms has focused on transition-metal catalysts (primarily, Pt, $\mathrm{Pd}, \mathrm{Rh}$, and $\mathrm{Ni}$ ). However, a much wider variety of catalysts are used in industrial practice. For example, the chemistry of zeolite-based catalysts is quite different from the chemistry in precious-metal catalysts. Thus, there are important opportunities to develop detailed reaction mechanisms for other catalysts and catalyst classes. An important topic in gas-to-liquids chemistry (e.g., methane dehydroaromatization, MDA) is the development and use of bi-functional catalysts. In the case of MDA, Mo/zeolite catalysts are prominent. Methane is first activated on molybdenum-carbide sites, with subsequent oligomerization and cyclization proceeding on zeolite Brønsted-acid sites [40, 41].

To be practical, using the detailed reaction mechanisms requires a richer software infrastructure than is needed to model a few global reactions. At present there are several alternative and available software implementations. In most cases, the reaction-description taxonomy generally follows the one proposed by Coltrin, et al. $[42,43]$ and implemented in the Chemкin software [44]. Other implementations include Deтснем ${ }^{2}$ and DARs ${ }^{3}$. Most high-level computational fluid dynamics (CFD) software (e.g., ANSYS FLUENT ${ }^{4}$ and CDadapco STAR-CCM ${ }^{5}$ ) has capabilities to implement de- ${ }^{402}$ tailed reaction mechanisms that can describe heteroge- ${ }_{403}$ neous catalysis. The CANTERA software ${ }^{6}$ that was de- ${ }^{404}$ veloped by Prof. David Goodwin (Caltech) is differ- 405 ent from the foregoing implementations. The Cantera 406 software, which is object-oriented and implemented in 407 $\mathrm{C}++$, is freely available and community supported. $\quad 408$

The development and validation of detailed reaction ${ }^{409}$ mechanisms are difficult and time consuming processes. ${ }^{410}$ Fortunately, a variety of reaction mechanisms have been ${ }^{411}$ made freely available from the group of Prof. Olaf Deutschmann (Karlsruhe Institute of Technology) ${ }^{7}$. Reaction mechanisms can be downloaded electronically in commonly used formats. Even in cases where one of the Deutschmann mechanisms may not be entirely suitable for a particular application, it may well provide a good starting point for further extension or development.

\footnotetext{
${ }^{2}$ http://www.detchem.com

${ }^{3}$ http://www.cd-adapco.com/products/star-ccm/dars

${ }^{4}$ http://www.ansys.com

${ }^{5}$ http://www.cd-adapco.com

${ }^{6} \mathrm{http}: / / \mathrm{www} . c a n t e r a . o r g$

${ }^{7}$ http://www.detchem.com/mechanisms.html
}

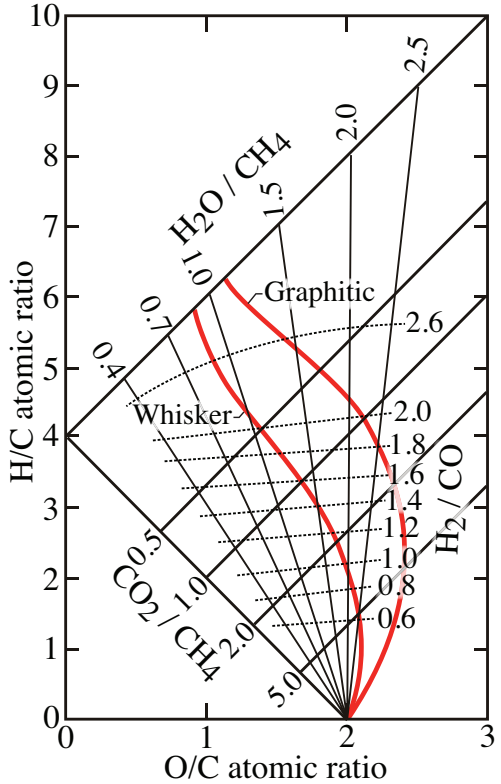

Figure 3: Carbon formation limits for graphitic carbon and surface whisker carbon on a $250 \mathrm{~nm} \mathrm{Ni}$ catalyst as functions of the feed composition at 25.5 bar and $950{ }^{\circ} \mathrm{C}$. The operating conditions span between fully dry reforming $\left(\mathrm{O} / \mathrm{C}=2, \mathrm{H}_{2} \mathrm{O} / \mathrm{CH}_{4}=0\right)$, fully steam reforming $\left(\mathrm{H} / \mathrm{C}=4, \mathrm{CO}_{2} / \mathrm{CH}_{4}=0\right)$ or steam and dry reforming combined regimes. This chart is reproduced from Rostrup-Nielsen and Christiansen $[5,45]$.

\subsection{Carbon deposits}

Catalyst fouling carbon deposition is often problematic in hydrocarbon processing, including reforming. The deposits may be graphic carbon (coke) that grows as a film on the active catalyst. The deposits may also be polyaromatic hydrocarbons (PAH), which are formed in the gas phase and deposit on the catalyst or they may be formed directly on the catalyst. Stated globally, the formation of solid carbon $\mathrm{C}(\mathrm{s})$ can follow several routes. The Boudouard reaction,

$$
2 \mathrm{CO} \rightleftharpoons \mathrm{C}(\mathrm{s})+\mathrm{CO}_{2},
$$

describes $\mathrm{CO}$ disproportionation. Other pathways include $\mathrm{CO}$ reduction,

$$
\mathrm{CO}+\mathrm{H}_{2} \rightleftharpoons \mathrm{C}(\mathrm{s})+\mathrm{H}_{2} \mathrm{O},
$$




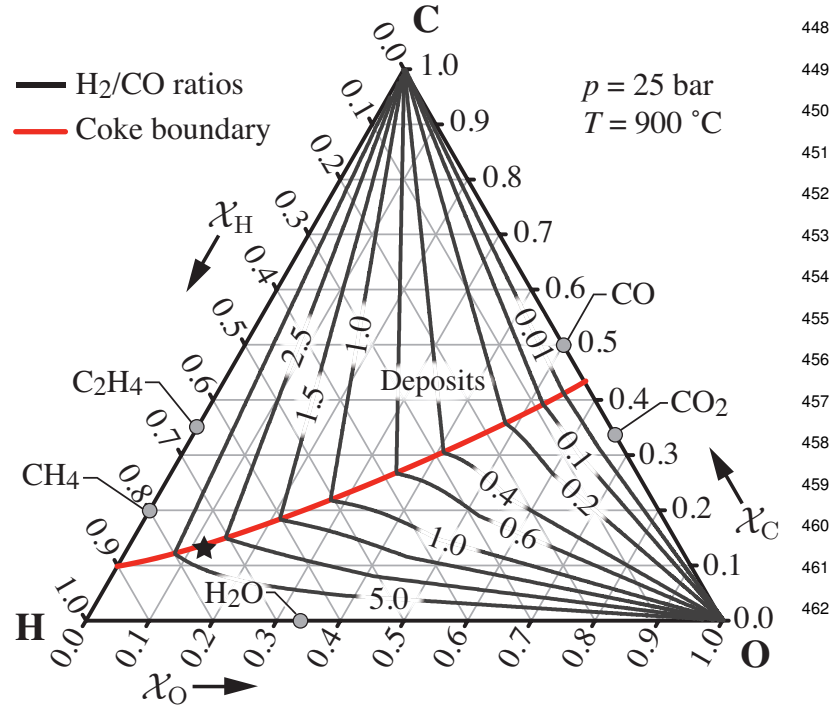

Figure 4: Ternary chart showing the equilibrium coke limit and the ${ }^{463}$ $\mathrm{H}_{2} / \mathrm{CO}$ ratio for mixtures of species containing hydrogen, carbon, and 464 oxygen.

called "whisker" carbon [46, 47]. The whisker carbon is mechanically strong. The whiskers not only deactivate the catalyst, but can also cause catalyst pellets to ${ }^{467}$ fracture and break apart. Whisker growth and particle fracture lead to increasing pressure drop within the cat- 468 alyst bed, eventually requiring process shutdown. After sufficiently severe degradation, catalyst regeneration may no longer be possible and the catalyst bed must be replaced.

The carbon formation can be reasonably and easily 471 estimated from equilibrium thermodynamics. Figure 3472 shows an interesting representation of the $\mathrm{CH}_{4}-\mathrm{H}_{2} \mathrm{O}-{ }_{473}$ $\mathrm{CO}_{2}$ reforming operating space [5]. The primary ab- ${ }_{474}$ scissa and ordinate represent the $\mathrm{O} / \mathrm{C}$ and $\mathrm{H} / \mathrm{C}$ atomic 475 ratios, respectively. The nonlinear axes on the $45^{\circ}$ bias 476 represent the $\mathrm{H}_{2} \mathrm{O} / \mathrm{CH}_{4}$ and $\mathrm{CO}_{2} / \mathrm{CH}_{4}$ feed ratios. The 477 dashed lines represent the equilibrium $\mathrm{H}_{2} / \mathrm{CO}$ ratios of ${ }_{478}$ the resulting syngas at $T=950{ }^{\circ} \mathrm{C}$ and $p=25.5$ bar. 479 The thick red curved lines represent different equilib- 480 rium coke limits, with the region to the left of the lines 481 being in coking regime. The right-most line represents ${ }_{482}$ graphite and the left-most line represents whisker car- ${ }_{483}$ bon. Although equilibrium estimates are useful, at least ${ }^{484}$ qualitatively, caution must be exercised in using a chart ${ }_{485}$ such as that in Fig. 3. The actual syngas composition 486 and the coke limits depend on the particular catalyst as ${ }_{487}$ well as the operating temperature and pressure. Also, ${ }_{488}$ this chart is not designed to accommodate CPOX or 489 ATR conditions.
Sasaki and Teraoka explored the regimes in which graphitic carbon can be formed under equilibrium conditions [48]. They represented the results in the form of ternary charts, such as the one shown in Fig. 4. The feed composition is represented in terms of its elemental composition, and the equilibrium composition is computed in the usual way by minimizing the Gibbs free energy. In the C-H-O ternary diagram (i.e., Fig. 4), the coordinates of a feed mixture having the species mole fractions $X_{k}$ can be represented using the element fractions $X_{e}$ of carbon $(e=\mathrm{C})$, hydrogen $(e=\mathrm{H})$, and oxygen $(e=\mathrm{O})$. Because the ternary chart considers hydrogen, oxygen, and carbon, a very wide range of feed mixtures are accommodated. The element fractions are easily evaluated as

$$
\mathcal{X}_{e}=\frac{\sum_{k} X_{k} n_{k, e}}{\sum_{e \in\{\mathrm{C}, \mathrm{H}, \mathrm{O}\}} \sum_{k} X_{k} n_{k, e}},
$$

where $n_{k, e}$ is number of the eth element in the $k$ th species. The three values of $\mathcal{X}_{e}$ form the particular coordinates of the ternary chart. To be more specific, the individual $\mathcal{X}_{e}$ can be evaluated as

$$
\begin{gathered}
\mathcal{X}_{\mathrm{C}}=\frac{\sum_{k} X_{k} n_{k, \mathrm{C}}}{\sum_{k} X_{k}\left(n_{k, \mathrm{C}}+n_{k, \mathrm{H}}+n_{k, \mathrm{O}}\right)} \\
\mathcal{X}_{\mathrm{H}}=\frac{\sum_{k} X_{k} n_{k, \mathrm{H}}}{\sum_{k} X_{k}\left(n_{k, \mathrm{C}}+n_{k, \mathrm{H}}+n_{k, \mathrm{O}}\right)} \\
\mathcal{X}_{\mathrm{O}}=\frac{\sum_{k} X_{k} n_{k, \mathrm{O}}}{\sum_{k} X_{k}\left(n_{k, \mathrm{C}}+n_{k, \mathrm{H}}+n_{k, \mathrm{O}}\right)}
\end{gathered}
$$

From the definitions, it must be the case $X_{\mathrm{C}}+\mathcal{X}_{\mathrm{H}}+\mathcal{X}_{\mathrm{O}}=$ 1. Only two of the three $\mathcal{X}_{e}$ values are needed to enter the chart. One of the values is redundant.

Figure 4 shows contours of the equilibrium $\mathrm{H}_{2} / \mathrm{CO}$ ratio that results from particular feed mixtures (at $T=$ $\left.900{ }^{\circ} \mathrm{C}, p=25 \mathrm{bar}\right)$. The thick red line indicates the equilibrium graphite deposition boundary. Below the line, no solid carbon is formed at equilibrium. Above the line, equilibrium carbon is stable. As an example, the "star" symbol is for an equimolar mixture of $\mathrm{CH}_{4}$ and $\mathrm{H}_{2} \mathrm{O}$ (i.e., the stoichiometry of Eq. 1). As can be anticipated from Eq. 1, the equilibrium $\mathrm{H}_{2} / \mathrm{CO}$ ratio is approximately three. It is not exactly three because the equilibrium computation involves many more species than are in the single global reaction. The star symbol resides essentially on the carbon-deposition boundary, indicating a poor operating point. However, it should be noted that the equilibrium graphite line is not necessarily a conservative estimate for coke formation. That is, considering kinetic behavior on actual catalysts carbon deposits may be observed in regions below the equilibrium graphite boundary. 
The syngas composition is a very important consider- ${ }_{542}$ ation, depending on the intended downstream process. ${ }^{443}$ For example, the $\mathrm{H}_{2} / \mathrm{CO}$ ratio should ideally be close ${ }_{544}$ to two if the syngas is being fed to a Fischer-Tropsch ${ }_{545}$ process (Eq. 6) or is being used for methanol synthesis ${ }_{546}$ (Eq. 5). Figure 4 can be used to estimate the effects of ${ }_{547}$ alternative inlet feed mixtures on the equilibrium $\mathrm{H}_{2} / \mathrm{CO}{ }_{548}$ ratio.

It is important to run a reformer in a regime that ef- 550 fectively converts the methane and avoids coking, but 551 also yields the desired $\mathrm{CO} / \mathrm{H}_{2}$ ratio. Using $\mathrm{Ni}$ cat- 552 alysts at high pressure and temperature, coke forma- ${ }_{553}$ tion is inevitable with the stoichiometric feed composi- ${ }_{554}$ tions for either steam- $\left(\mathrm{H}_{2} \mathrm{O} / \mathrm{CH}_{4}=1\right)$ or dry-reforming 555 $\left(\mathrm{CO}_{2} / \mathrm{CH}_{4}=1\right)$ processes. Thus, practical reactors are 556 operated with excess $\mathrm{H}_{2} \mathrm{O}$ and $\mathrm{CO}_{2}$. In these cases, ${ }_{557}$ additional heating is required for steam generation and ${ }_{558}$ $\mathrm{CO}_{2}$ preheating. Also, additional downstream separa- 559 tion costs are required to remove $\mathrm{H}_{2} \mathrm{O}$ and $\mathrm{CO}_{2}$.

\subsection{Other catalyst degradation mechanisms}

In addition to coke formation, there are numerous 563 other mechanisms that act to diminish catalytic activ- 564 ity [49]. Degradation is usually the result of cou- 565 pled chemical, thermal, and mechanical phenomena. In 566 some cases catalyst degradation can be reversed and in ${ }^{567}$ other cases the degradation is irreversible. The consid- ${ }_{568}$ eration of catalyst degradation, and possible regenera- 569 tion, is usually an important aspect of process design 570 and reactor development.

Catalyst poisoning is caused by the strong adsorption 572 of reactants, products, or the impurities on active cat- 573 alytic active sites, thus blocking the desired catalytic 574 function. In addition to physically blocking adsorp- 575 tion sites, adsorbed poisons may also induce deleterious 576 changes in the electronic or geometric structure of the 577 surface [50,51]. For example, CO has a very high ad- 578 sorption probability on $\mathrm{Rh}$ and $\mathrm{Ni}$ catalysts at low tem- 579 peratures $\left(T \leq 500^{\circ} \mathrm{C}\right)[31,33]$. However, such adsorp- 580 tion is reversible. As temperature increases the equilib- 581 rium shifts toward lower $\mathrm{CO}$ adsorption and desorption 582 rates increase.

Unlike CO, some poisoning effects can be irre- 584 versible. For example, sulfur compounds can inter- 585 act unfavorably with transition-metal catalysts. In 586 addition to strong adsorption, the sulfur can react ${ }_{587}$ to form metal sulfides. Such behavior is particu- ${ }_{588}$ larly active with $\mathrm{Ni}$ and Co catalysts. Sulfur reactiv- ${ }_{589}$ ity with other metal catalysts is generally ordered as 590 $\mathrm{Ni}>\mathrm{Co}>\mathrm{Rh}>\mathrm{Ru}>\mathrm{Re}>\mathrm{Pt}>\mathrm{Pd}$ [52]. Sulfur poisoning can 591 be severe, meaning very low levels (e.g., $\leq 1 \mathrm{ppm}$ ) can ${ }_{592}$ severely reduce the catalytic activity [53-55]. Because 593 sulfur is prevalent in petroleum- and bio-derived fuels, understanding and controlling sulfur-catalyst interactions is important.

There is current research on designing sulfur tolerant catalysts by modifying metal catalysts. Modifications include changing the electron deficiency of noble metals via interaction with an acidic support or introducing a secondary metal $[52,56]$. Doping Ni catalysts with a second sulfur-tolerant metal such as $\mathrm{Rh}, \mathrm{Ru}, \mathrm{La}$ and $\mathrm{B}$ is known to increase the sulfur resistance [57-59]. Although sulfur usually decreases catalytic activity, there may also be some benefits. For example, Holdør-Topsoe has developed a process in which sulfur $\left(\mathrm{H}_{2} \mathrm{~S}\right)$ is used beneficially to reduce carbon deposits [60, 17].

Ideally, the catalysts themselves do not react. In fact, catalysts can and do undergo chemical transformations. At high temperature and in the presence of excess oxygen metal catalysts can be oxidized (e.g., Ni to $\mathrm{NiO}[61,62]$, or $\mathrm{Rh}$ to $\left.\mathrm{RhO}_{x}[63,64]\right)$. In hightemperature $\mathrm{H}_{2}$-rich reducing environments, a metaloxide catalyst can be reduced to its comparatively inactive metallic form (e.g, PdO to Pd [65]). Such relatively straightforward redox processes can often be reversed. However, catalyst regeneration requires changing operating conditions and non-productive reactor time.

Some chemical transformations are largely irreversible. Metal catalyst particles may react with the underlying ceramic (e.g., $\mathrm{Al}_{2} \mathrm{O}_{3}, \mathrm{CeO}_{2}$ ) support structure. A typical example is the interaction of an alumina support with $\mathrm{Rh}$ or $\mathrm{Ni}$, forming $\mathrm{Rh}\left(\mathrm{AlO}_{2}\right)_{y}$ and $\mathrm{NiAl}_{2} \mathrm{O}_{4}$. Reactions between steam and zeolite-based catalysts can remove $\mathrm{Al}$ from the zeolite framework (dealuminization), causing irreversible loss of zeolite crystallinity and catalytic activity.

Especially at high temperatures active catalysts can sinter together, causing a loss of active surface area that manifests itself as effective deactivation [66-68]. High temperatures can also cause changes the support structure, decreasing the accessible surface and hence the activity [69].

Catalyst particles or pellets can be damaged mechanically as they interact physically, especially in reactors operating at high space velocities. As particles fracture, catalytic activity can decrease irreversibly. Another mechanical degradation can occur on metal reactor walls. The reaction of deposited carbon on steel reactor walls can cause a damaging effect called "metal dusting." Although not affecting the catalyst directly, reactor damage of any sort is problematic.

Broadly speaking, most degradation processes are exacerbated at higher temperatures. Thus, an important aspect of process and reactor design is the control of 
temperature and temperature variations. As discussed 642 subsequently, novel reactor-design approaches that in- 643 clude microchannel reactors and permselective mem- 644 branes can assist in achieving thermal control.

\section{Reformer reactor technology}

\subsection{Industrial-scale reformers}

Figure 5 illustrates a large-scale combustion-fired steam reformer. The catalysts are housed in long narrow tubes, which are typically around $10-20 \mathrm{~cm}$ in diameter and 10-12 $\mathrm{m}$ long. Such reformers may have several hundred catalyst tubes. In this configuration, the heat is provided by down-fired natural-gas flames. The combustion exhaust gases are captured in large rectangular ducts called "coffins." The hot exhaust gases are used in recuperating heat exchangers to preheat the methanesteam feed stream.

The feed mixture enters the catalyst tubes at the top and flows downward through the packed-bed catalysts. The methane-steam flow rate (and hence the magnitude of the endotherm) and the combustion heat must be balanced such as to maintain the catalyst bed above $800{ }^{\circ} \mathrm{C}$. As illustrated in the inset, the bed is typically configured as catalyst-impregnated ceramic pellets. The pellet design and the catalyst packing depends on operational tradeoffs, such as between effective catalyst area and flow pressure drop.

Reformers can be designed with alternative burner configurations, including top fire, bottom fire, terrace fire, and side fire $[5,70]$. An important consideration is to establish high heat flux while maintaining temperature uniformity throughout the catalyst bed. Yet another consideration is concerned with interactions between the flame and the tube materials. Because the metal tubes are directly exposed to the flame, the hightemperature oxidizing environment can irreversibly corrode and damage the reformer tubes. Nonuniform temperature profiles and local hot spots can also cause performance and materials degradation, including catalyst activity loss and particle fracture.

\subsection{Process intensification in reformers}

Process intensification is broadly defined in terms of finding novel approaches that significantly improve performance [71]. One avenue is to combine unit processes in ways that greatly increase energy efficiency or reduce plant size. For example, consider two unit processes, one of which is exothermic and the other is endothermic. An intensified process seeks to closely couple the two processes such that the excess heat from the exothermic process can be used directly to support the endothermic process. Microchannel heat exchangers and reactors offer a route to process intensification. Other opportunities are associated with membranes reactors that integrate separation processes.

Figure 6 illustrates a microchannel reactor that combines an exothermic process (say methane combustion) with an endothermic process (say steam reforming) [75]. Another alternative is to flow waste heat from one process through one layer of channels to support endothermic catalysis in the adjoining layer of channels [76-79]. The "microchannel" height is typically on the order of a fraction of a millimeter. Microchannel reactors have two significant benefits. One is the high heat and mass transfer associated with the small channel dimensions. The Nusselt (dimensionless heat transfer coefficient) and Sherwood (dimensionless mass transfer coefficient) numbers are constants for laminar flow in small channels. The Nusselt and Sherwood number values depend on the channel aspect ratio, but are independent of the channel dimensions [80]. Thus, as the channel dimensions decrease, the heat and mass transfer coefficients increase. A second benefit of the microchannel design is the closely coupled heat transfer between layers. Such microchannel designs can deliver very good performance in a compact reactor [81, 82].

Although microchannel reactors such as illustrated in Fig. 6 can be effective, there can also be some problematic aspects. The reactors often need to be fabricated from high-temperature metals $[83,84]$, which can be expensive and limited in temperature ranges. The reactors can be fabricated from ceramics [85], which expands operating ranges but could suffer from reduced mechanical strength. Especially in counter-flow arrangements, design and fabrication of the flow manifolding can be

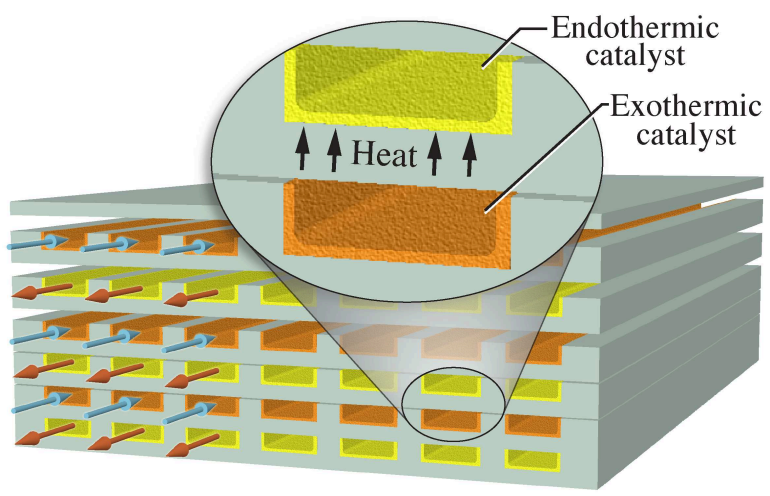

Figure 6: Illustration of a microchannel reactor with alternating layers of endothermic and exothermic catalysts. As illustrated here the catalysts are washcoated onto the channel walls. 


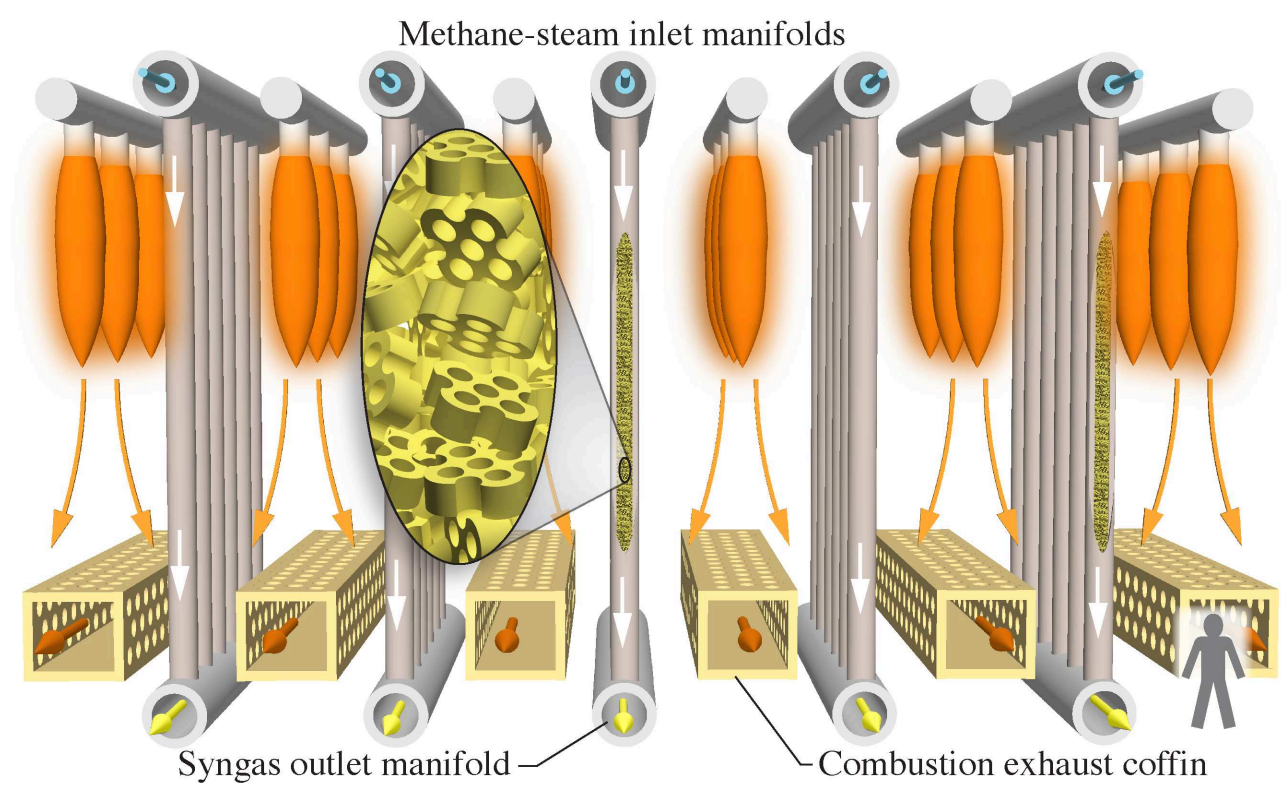

Figure 5: Methane steam reformer in a top-fired configuration. The stick figure provides some sense of the scale.

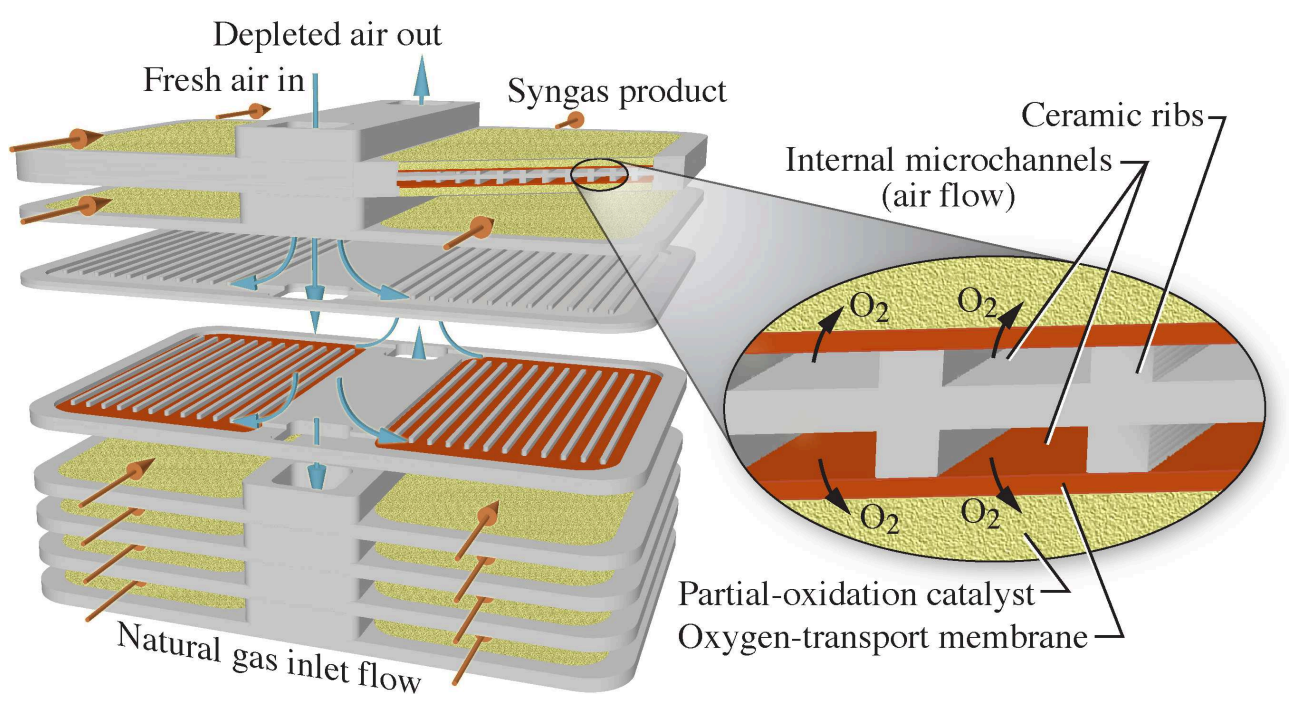

Figure 7: Planar membrane-assisted partial-oxidation syngas reactor developed by Air Products [72-74].

difficult. Once a microchannel reactor is fabricated and ${ }_{687}$ sealed, incorporating the catalyst layer can be difficult. 688 Removing and replacing deactivated catalysts can be 689 even more difficult. There are practical operational ben- 690 efits associated with designs that facilitate disassembly 691 and catalyst replacement [86]. The channels shown in 692 Fig. 6 are in a counter-flow arrangement and config- 693 ured as individual layers that can be mechanically com- 694 pressed together. Although this layout may facilitate catalyst maintenance, sealing and manifolding is diffi- cult.

Figure 7 illustrates a process-intensified reactor for a partial-oxidation process that has been developed and demonstrated by Air Products ${ }^{8}$ and Ceramatec ${ }^{9}[72$ 74]. The reactor is configured as multi-functional planar blades. Natural gas flows over the external surfaces of the blades, which house partial-oxidation catalysts within a porous-ceramic support structure. Air

\footnotetext{
${ }^{8}$ www.airproducts.com

${ }^{9}$ www.ceramate.com
} 
Table 2: Global reactions in Fischer-Tropsch synthesis.

1. $\quad(2 n+1) \mathrm{H}_{2}+n \mathrm{CO} \leftrightharpoons \mathrm{C}_{n} \mathrm{H}_{2 n+2}+n \mathrm{H}_{2} \mathrm{O}$

$2 n \mathrm{H}_{2}+n \mathrm{CO} \leftrightharpoons \mathrm{C}_{n} \mathrm{H}_{2 n}+n \mathrm{H}_{2} \mathrm{O}$

$2 n \mathrm{H}_{2}+n \mathrm{CO} \leftrightharpoons \mathrm{C}_{n} \mathrm{H}_{2 n+2} \mathrm{O}+(n-1) \mathrm{H}_{2} \mathrm{O}$

$(2 n-1) \mathrm{H}_{2}+n \mathrm{CO} \leftrightharpoons \mathrm{C}_{n} \mathrm{H}_{2 n} \mathrm{O}+(n-1) \mathrm{H}_{2} \mathrm{O}$

$(2 n-2) \mathrm{H}_{2}+n \mathrm{CO} \leftrightharpoons \mathrm{C}_{n} \mathrm{H}_{2 n} \mathrm{O}_{2}+(n-2) \mathrm{H}_{2} \mathrm{O}$

flows through microchannels that are housed within the blades. The air flow and the catalyst structures are separated by a thin ion-transport membrane (ITM). Membrane materials such as calcium-doped lanthanum ferrites $\left(\mathrm{La}_{x} \mathrm{Ca}_{1-x} \mathrm{FeO}_{3-\delta}\right.$, LCF) are perovskite mixed ionic-electronic conductors (MIEC) that conduct oxide ions. The membrane serves to separate oxygen from air and deliver pure oxygen to the catalyst structure where it reacts with the natural gas. The partial-oxidation pro- 736 cess produces syngas according to Eq. 3 .

Figure 8 illustrates a process-intensified approach that has been developed and demonstrated by Praxair, Inc. ${ }^{10}$ [87-89]. In this case, intensification is achieved by in-situ air separation and a combination of endothermic and exothermic processes. Figure 8 shows one panel of a multi-panel reactor. Each panel is composed of multiple U-shaped reformer tubes and partialoxidation tubes. A mixture of steam and methane enters the endothermic steam-reformer tubes, which are packed with catalyst pellets. The flow rates are set such that the methane is only partially reformed, with some methane remaining in the exit stream.

The partially reformed mixture from the steamreformer tubes is directed into the partial-oxidation tubes. These tubes feature a mixed-conducting iontransport membrane that separates oxygen from an external air flow. As illustrated in the upper-right balloon of Fig. 8, the partial-oxidation tubes have a relatively complex architecture. The structural support is a chemically inert porous ceramic tube. The first exterior layer is a porous partial-oxidation catalyst. The next layer is the ceramic oxygen transport membrane. The final outer layer is an oxygen-reduction catalyst that facilitates the incorporation of oxygen into the membrane. Because only oxide-ions are transported through the membrane, the oxygen is separated from air. The partial-oxidation tubes are hot as a result of exothermic reactions. The high-temperature tubes radiate to the relatively cooler steam-reforming tubes, thus supplying the heat needed to the support the endothermic steam reforming.

\footnotetext{
${ }^{10}$ www.praxair.com
}

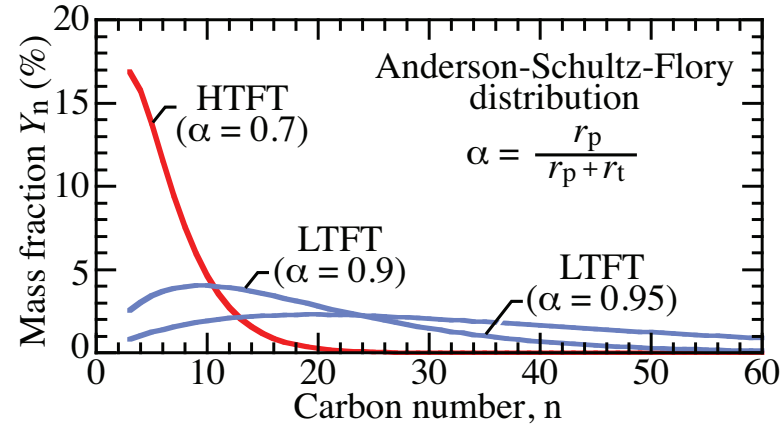

Figure 9: Mass-based distribution of product species as functions of carbon number.

\section{Fischer-Tropsch synthesis}

Fischer-Tropsch synthesis is an intermediate step between syngas and the subsequent refining to fuels or chemicals. The chemistry and the technology are well known and extensively documented $[6,11,90]$. Thus, the present paper provides only a superficial discussion, concentrating primarily on alternative reactor technologies and opportunities for process intensification.

Although the actual chemistry is complex and involves a great many elementary steps, Table 2 summarizes the processes in terms of five global reactions $[90,91]$. The reactants are $\mathrm{H}_{2}$ and $\mathrm{CO}$ with the ratio of $\mathrm{H}_{2}$ to $\mathrm{CO}$ being approximately two. The products include alkanes $\left(\mathrm{C}_{n} \mathrm{H}_{2 n+2}\right)$, alkenes $\left(\mathrm{C}_{n} \mathrm{H}_{2 n}\right)$, alcohols and ethers $\left(\mathrm{C}_{n} \mathrm{H}_{2 n} \mathrm{O}\right)$, aldehydes and ketones $\left(\mathrm{C}_{n} \mathrm{H}_{2 n} \mathrm{O}\right)$, and carboxylic acids and esters $\left(\mathrm{C}_{n} \mathrm{H}_{2 n+2} \mathrm{O}_{2}\right)$. In all cases, $\mathrm{H}_{2} \mathrm{O}$ is a reaction product. The specific product distribution depends on operating conditions and the catalyst.

In broad terms, the Fischer-Tropsch process can be categorized in terms of operating temperature and choice of catalyst, with both considerations affecting the product distributions. High temperature (HTFT) is generally understood as $T>320^{\circ} \mathrm{C}$ with low temperature (LTFT) being $T<250{ }^{\circ} \mathrm{C}$. The catalysts are usually either iron-based or cobalt-based. The operating pressure is usually in the range of 10 to 30 bar.

The product distribution can be estimated using the Anderson-Schultz-Flory equation [92, 93],

$$
Y_{n}=n(1-\alpha)^{2} \alpha^{(n-1)},
$$

where $Y_{n}$ is the mass fraction of species with carbon number $n(n>2)$. The parameter $\alpha$ depends on the rates of chain propagation $r_{\mathrm{p}}$ and chain termination $r_{\mathrm{t}}$ on the catalysts,

$$
\alpha=\frac{r_{\mathrm{p}}}{r_{\mathrm{p}}+r_{\mathrm{t}}} .
$$



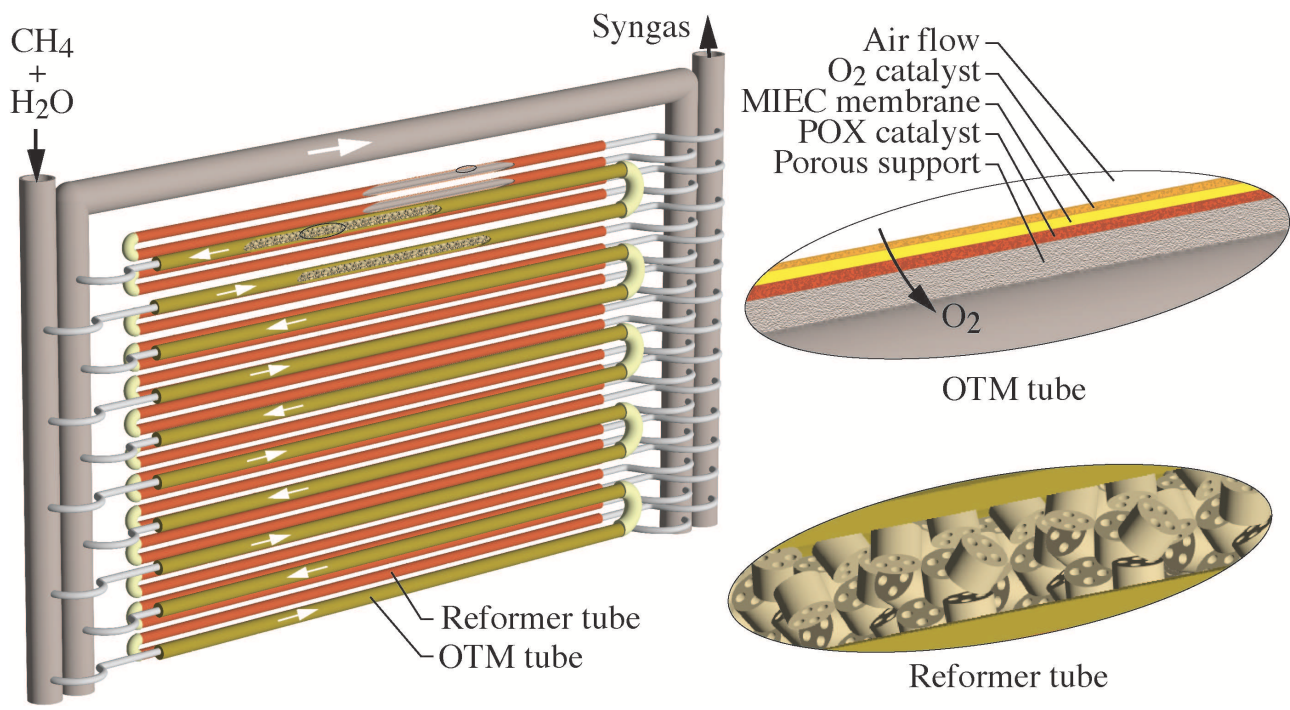

Figure 8: Illustration of an integrated air-separation and autothermal reforming reactor developed by Praxair [87-89].

As temperature increases, the desorption rates increase, which diminishes the chain-propagation rates and hence decreases $\alpha$. High-temperature Fischer-Tropsch processes are characterized by $0.65 \leq \alpha \leq 0.7$ and lowtemperature Fischer-Tropsch processes are characterized by $0.85 \leq \alpha \leq 0.95$.

Figure 9 shows the distribution of product species with carbon number $n$ as a function of carbon number. As the temperature increases the product species shift toward lower carbon numbers. Lowtemperature Fischer-Tropsch processes deliver carbonnumber product distributions with peaks in the mid carbon-number ranges. It is at least interesting to note that LTFT processes with $\alpha \approx 0.9$ delivers a carbonnumber distribution that is similar to light crude oil.

Because the reactions are exothermic (around $160 \mathrm{~kJ}$ $\mathrm{mol}^{-1}$ ), the process itself produces substantial heat. If the heat is not removed, the relatively low operating temperature for the Fischer-Tropsch process cannot be maintained. Moreover, depending on how the heat is removed, maintaining temperature uniformity through the catalyst bed can be difficult. The heat-removal from Fischer-Tropsch processes is typically accomplished with pressurized boiling water. By controlling pressure, the saturation temperature can be controlled. By controlling the water flow rate, the requisite heat can be removed.

\subsection{Large-scale Fischer-Tropsch}

At the refinery scale (thousands of barrels per day), 799 Fischer-Tropsch processes have been implemented in 800

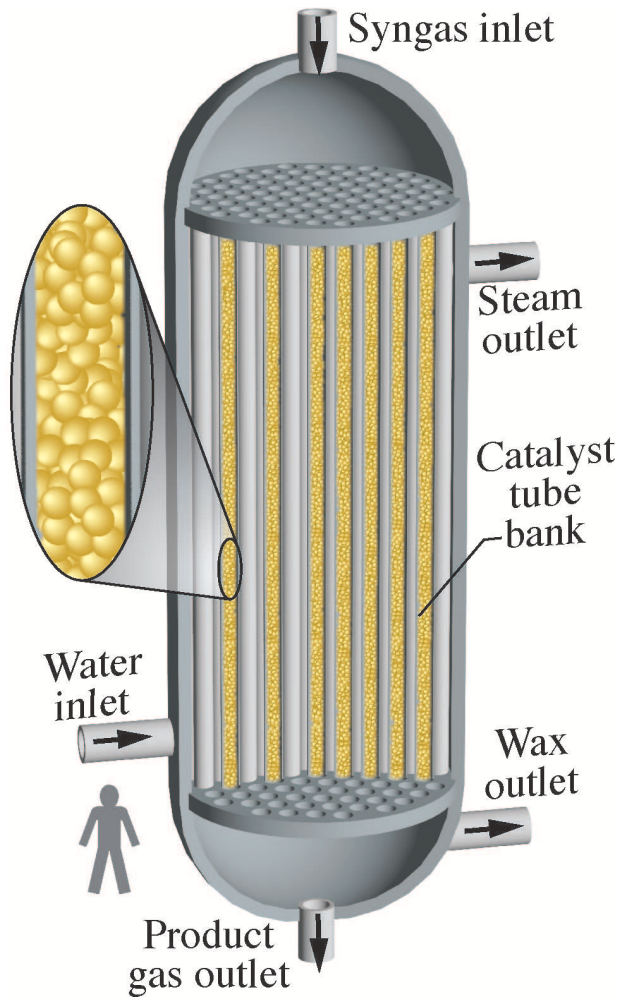

Figure 10: Illustration of large-scale packed-bed Low-Temperature Fischer-Tropsch (LTFT) reactor.

a variety of large-scale pressurized catalytic reactors. These include fixed-bed, fluidized-bed, and slurrybubble reactors [94]. Figure 10 illustrates some aspects 


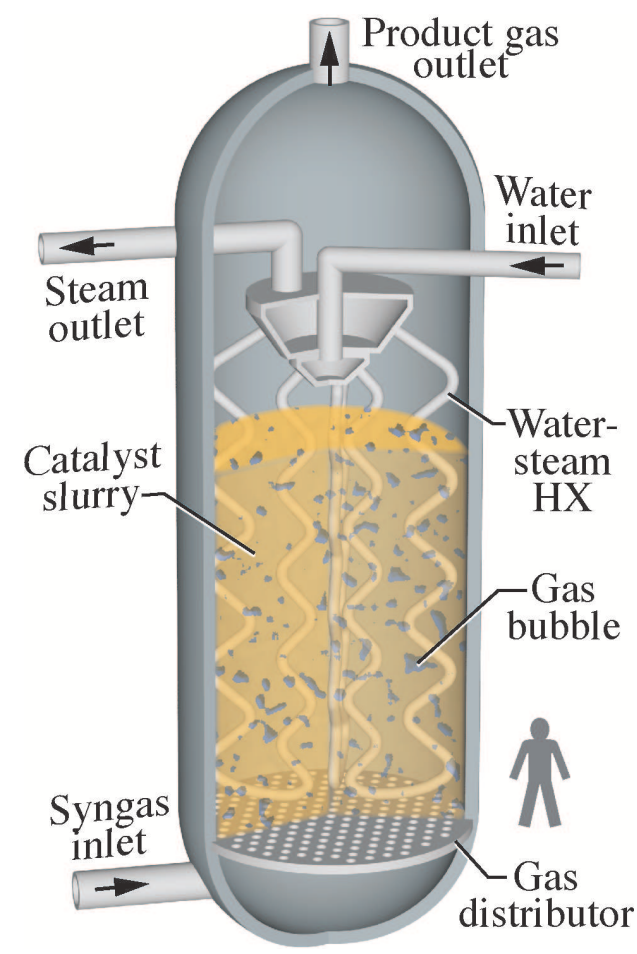

Figure 11: Illustration of large-scale slurry-bubble Low-Temperature Fischer-Tropsch (LTFT) reactor. The heat-exchanger tubes as shown 825 are stylized and not intended to represent any particular reactor.

of a fixed-bed LTFT reactor. Syngas enters at the top and flows downward through an array of long packedbed catalyst tubes. The product exits through the lower section of the reactor, with the large paraffins (waxes) being separated from the more volatile products. A large LTFT reactor could have several hundred catalyst tubes. Pressurized water circulates in the space outside the catalyst tubes, with steam exiting at the top of the tube array. Maintaining radial and axial temperature uniformity is an important design and operational challenge [95]. The relatively narrow and long tubes tend to promote radially uniform plug-flow through the catalyst beds. Although the chemistry and the catalysts are quite different, there is at least a superficial similarity with the tubes in large-scale reformers such as illustrated in Fig. 5.

Although the designs are more complex, fluidizedbed reactors offer one approach to maintaining better temperature control. Fluidizing and circulating the catalyst particles promotes mixing and enhances heat transfer to internal cooling media. As in the fixed-bed reactors, high-pressure water is typically used for cooling. In the case of fluidized-bed reactors, the coolant is circulated through internal heat exchangers. Although

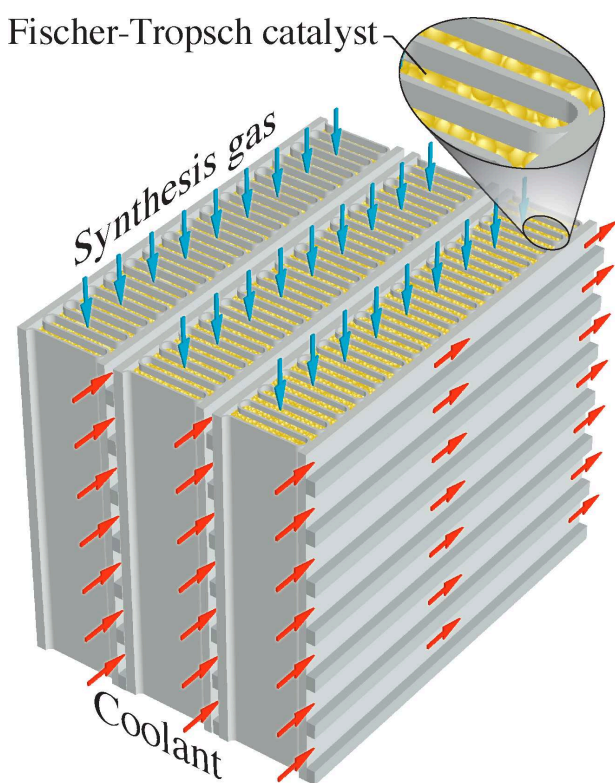

Figure 12: Illustration of segment of a microchannel Fischer-Tropsch reactor, generally modeled after the Velocys approach. The individual microchannels have characteristic dimensions on the order of one millimeter or less.

the reactor manufacturers do not disclose details of the coolant circuits, one expects that they are implemented as arrays of tubes throughout the fluidized beds.

Figure 11 illustrates features of a slurry-bubble Fischer-Tropsch reactor [96]. In such reactors the catalysts are carried in an oil-based slurry that is intended to be chemically inert. Syngas enters from below, forming bubbles within the slurry. High pressure water circulates within heat-exchanger tubes. The reaction chemistry proceeds on the distributed catalyst surfaces, with gas-phase reaction products contributing to the bubbles. The gas flow and the bubbles agitate the slurry, promoting good heat-transfer coupling between the slurry and the heat exchanger tubes. The fluid motion also promotes mixing that tends to limit temperature variations within the system.

\subsection{Microchannel reactors}

Although the large-scale Fischer-Tropsch reactors are being operated with commercial success, there is great interest in applying process-intensification approaches to reduce the reactor size and improve performance $[78,7,97-99,76,100]$. Figure 12 illustrates a small section of a microchannel design that is modeled after the approach taken by Velocys ${ }^{11}$. In this design

\footnotetext{
${ }^{11}$ www.velocys.com
} 


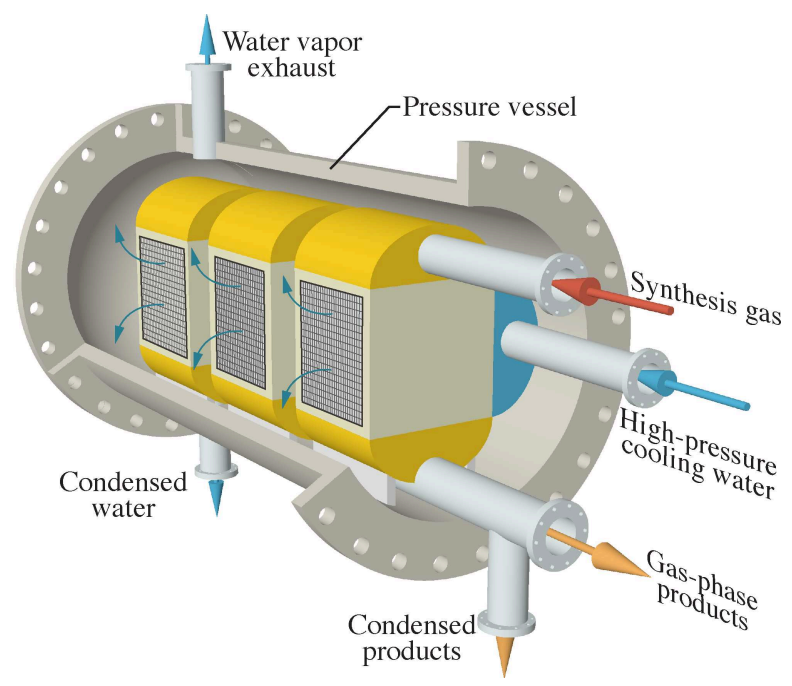
pressure vessel, generally modeled after the Velocys approach. Each of the three microchannel reactors have overall characteristic dimensions of around one meter.

the catalyst is housed within wave-like fin structures that promote heat transfer from the catalyst bed. Syngas enters from the top and flows downward through the catalyst bed, with Fischer-Tropsch products exiting at the bottom. The reaction heat is removed by the pressurized-water coolant within cross-flow microchannels. The fin spacing and coolant channels are on the order of a millimeter. The highly efficient heat transfer associated with microchannels delivers a compact, high-performance reactor.

Figure 13 illustrates the packaging of three microchannel Fischer-Tropsch reactors within a pressure vessel. Each of the reactors, which have overall dimensions on the order of a meter, are composed of microscale features as illustrated in Fig. 12. Syngas enters the reactors' catalyst sections from above via a gasdistribution manifold. The Fischer-Tropsch products are collected through manifolds at the bottom of the reactors. Pressurized cooling water enters through manifolds that feed the microchannel arrays, with the watersteam exhaust mixture leaving the reactors into the outer pressure-vessel housing. Water vapor exhausts at the top of the pressure vessel and condensed water drains through the bottom.

Microchannel-based Fischer-Tropsch reactors are now mature to the point that they are being offered commercially by Velocys ${ }^{12}$. The reactor illustrated in cartoon form by Fig. 13 is demonstrated to deliver approx-

\footnotetext{
${ }^{12}$ www.velocys.com
}

imately 175 barrels of Fischer-Tropsch products per day. Thus, this technology is particularly well suited for small-scale GTL production with remote or stranded gas sources.

\section{Oxidative coupling of methane}

Although the Fischer-Tropsch technology is mature and practiced commercially, direct conversion of natural gas offers some potential benefits. In this context, "direct conversion" means processing that is not based on first producing synthesis gas [101]. One of the possible direct-conversion routes is Oxidative Coupling of Methane (OCM), which is intended to produce ethylene as the primary product.

The OCM process, which first proposed by Keller and Bhasin in 1982 [102], can be represented globally as

$$
2 \mathrm{CH}_{4}+\mathrm{O}_{2} \rightleftarrows \mathrm{C}_{2} \mathrm{H}_{4}+2 \mathrm{H}_{2} \mathrm{O} \text {. }
$$

This process usually operates at temperatures around $700{ }^{\circ} \mathrm{C}$ and requires a selective catalyst. The elevated temperature is needed to activate the methane and the catalyst promotes selectivity toward ethylene. Because of the elevated temperature and the presence of oxygen, there is general agreement that gas-phase chemistry plays a significant role in the overall process.

In addition to using different catalysts, the $\mathrm{CH}_{4} / \mathrm{O}_{2}$ feed ratio affects the process selectivity. According to Eq. 18 the process requires a stoichiometric $\mathrm{CH}_{4} / \mathrm{O}_{2}$ ratio of 2. However, at high temperatures and in an oxidizing environment the partial and total oxidation of methane and the $\mathrm{C}_{2}$ species compete with the desired OCM process. In practice OCM processes operate with large excesses of $\mathrm{CH}_{4}$ (typically, $5 \leq \mathrm{CH}_{4} / \mathrm{O}_{2} \leq 10$ ). Under $\mathrm{CH}_{4}$-rich conditions, the methane conversion is limited by the deficient $\mathrm{O}_{2}$ concentration. The desired $\mathrm{C}_{2}$ products are more stable at low $\mathrm{O}_{2}$ levels, resulting in higher $\mathrm{C}_{2}$ selectivity at low $\mathrm{O}_{2}$ partial pressures where methane conversion is low. In other words there is a trade-off between the $\mathrm{C}_{2}$ selectivity and yield. High $\mathrm{C}_{2}$ selectivity (e.g., $70 \%$ ) is possible when methane conversion is low (e.g., $\leq 20 \%$ ). In any case, there is always a significant competition between desired and undesired outcomes, with actual performance being a combination of multiple competing pathways.

The OCM process has been the subject of extensive research since its discovery in 1982 [103-114] and several reviews have been published [115-118]. Economic analyses suggest that commercial viability demands single-pass $\mathrm{C}_{2} \mathrm{H}_{4}$ yields that exceed $25 \%[119,1]$. To 
date, with one possible recent exception (Siluria Tech- 971 nologies, Inc. ${ }^{13}$ ), OCM has not yet achieved practical ${ }_{972}$ viability. Continued development of the OCM tech- 973 nology depends on improved catalysts as well as the 974 innovative concepts for reactor design. The following 975 sections are concerned primarily with opportunities for 976 process intensification and reactor development.

\subsection{OCM catalysts}

The OCM process depends on $\mathrm{C}_{2}$-selective cata- ${ }^{980}$ lysts that are stable at elevated temperature. Broadly ${ }^{981}$ speaking, two classes of catalysts are found to de- ${ }^{982}$ liver reasonable performance. One class is based on ${ }^{983}$ $\mathrm{La}_{2} \mathrm{O}_{3}$ that is doped with alkaline-earth metals $\left(\mathrm{Sr}, \mathrm{Mg}\right.$, ${ }^{984}$ Ca) [120-124]. The other class is broadly represented as ${ }^{985}$ $\mathrm{Mn} / \mathrm{Na}_{2} \mathrm{WO}_{4} / \mathrm{SiO}_{2}$ [125-129]. There is also consider- ${ }^{986}$ able literature on $\mathrm{Li} / \mathrm{MgO}$ as an OCM catalyst, but these ${ }^{987}$ materials are not practically viable because they are un- 988 stable under OCM operating conditions [130-136]. The ${ }^{989}$ $\mathrm{La}_{2} \mathrm{O}_{3}$ and $\mathrm{Li} / \mathrm{MgO}$ catalysts deliver moderate $\mathrm{C}_{2}$ yield 990 $(\leq 20 \%)$, but suffer significant stability problems. Dop- ${ }^{991}$ ing the $\mathrm{La}_{2} \mathrm{O}_{3}$ with $\mathrm{Sr}, \mathrm{CaO}$, or $\mathrm{CeO}_{2}$ can improve the ${ }^{992}$ catalyst performance. The maximum $\mathrm{C}_{2}$ yield reported ${ }^{993}$ over $\mathrm{Sr}-\mathrm{La}_{2} \mathrm{O}_{3}$ at $800{ }^{\circ} \mathrm{C}$ is $17 \%$ [137].

Despite the low $\mathrm{C}_{2}$ yield and durability problems, ${ }^{994}$ there is considerable experimental and theoretical re- 995 search focusing on the $\mathrm{Li} / \mathrm{MgO}$ catalysts. The relatively 996 simpler catalyst structure makes a fundamental under- 997 standing of the OCM chemistry more accessible than in 998 more complex catalysts [134-136].

The $\mathrm{Mn} / \mathrm{Na}_{2} \mathrm{WO}_{4} / \mathrm{SiO}_{2}$ materials were first identified 1000 as OCM catalysts by Fang, et al. [125]. The high- 1001 temperature stability enables operating the OCM reactors at sufficiently high temperatures to achieve good $\mathrm{C}_{2}$ yield. Experiments in laboratory-scale packed-bed re- ${ }^{1002}$ actors deliver $16-25 \% \mathrm{C}_{2}$ yield at $800{ }^{\circ} \mathrm{C}[125,138]$. A 2011 patent by Zarrinpashne et al. [139] reported ${ }^{1003}$ $27 \% \mathrm{C}_{2}$ yield at $850{ }^{\circ} \mathrm{C}$. The increased yield was attributed to the catalyst elemental composition and the catalyst-synthesis technique. Further improvements are ${ }_{1004}$ associated with doping the $\mathrm{Mn} / \mathrm{Na}_{2} \mathrm{WO}_{4} / \mathrm{SiO}_{2}$ catalysts ${ }_{1005}$ with alkali chlorides ( $\mathrm{LiCl}, \mathrm{NaCl}, \mathrm{KCl}, \mathrm{CsC})$, increasing ethylene yield up to $31 \%$ at $750{ }^{\circ} \mathrm{C}$ [129].

Recent research is focused on OCM catalysts that enable low-temperature $\left(T \leq 600{ }^{\circ} \mathrm{C}\right)$ performance. ${ }^{1006}$ The catalyst activity is found to depend not only on ${ }^{1007}$ the catalyst's metal composition, but also on particle 1008 size and morphology [140-143]. Nano-structured cat- 1009 alysts activate the methane at lower temperatures [111, 1010

\footnotetext{
${ }^{13}$ www.siluria.com
}

140]. Nano-structured (nanowire, nanorods, nanofibers) $\mathrm{La}_{2} \mathrm{O}_{3}, \mathrm{Sr}-\mathrm{La}_{2} \mathrm{O}_{3}$ and $\mathrm{La}_{2} \mathrm{O}_{3}-\mathrm{CeO}_{2}$ catalysts delivered superior OCM performance compared to the same catalysts in powder form [111, 141, 143, 142]. Song et al. [142] developed a stable $\mathrm{Sr}-\mathrm{La}_{2} \mathrm{O}_{3}$ nanofiber catalyst that delivered approximately $16 \% \mathrm{C}_{2}$ yield at $500{ }^{\circ} \mathrm{C}$, with the catalyst being stable up to $800^{\circ} \mathrm{C}$. The catalytic activity of nanorods and nonofibers is attributed to high surface areas, well defined crystalline structures, and the ability to form surface oxides [141].

Achieving economic viability depends on improving catalyst selectivity and/or reducing process temperature. The recent development of nano-structured catalysts has beneficially influenced the course of OCM technology. Recently, Siluria Technologies announced a commercial OCM process. However, their patent application reveals that their process does not achieve $25 \% \mathrm{C}_{2}$ singlepass yield [144]. Two different nanowire catalysts are considered. One that is composed of $20 \mathrm{wt} . \% \mathrm{Mg}, 5$ wt. $\% \mathrm{Na}$, and 75 wt. $\% \mathrm{La}_{2} \mathrm{O}_{3}$ delivers yields of approximately $12 \% \mathrm{C}_{2+}$ at $600{ }^{\circ} \mathrm{C}$ [145]. The other is $\mathrm{Ln} 1_{4-x} \mathrm{Ln} 2_{2-x} \mathrm{O}_{6}$ (Ln1 and $\mathrm{Ln} 2$ are rare-earth metals), which delivers $22.6 \% \mathrm{C}_{2+}$ yield.

\subsection{Reaction kinetics}

Although the details of OCM depend on the particular catalyst and specific operating conditions, there is general agreement that the reaction pathways are similar on all catalysts. The rate-limiting step is methane activation on the catalyst surface and in the gas phase to form methyl radicals. Possible surface reactions for methane activation include thermal cracking as

$$
\begin{gathered}
\mathrm{CH}_{4}+(\mathrm{s}) \rightarrow \mathrm{CH}_{4}(\mathrm{~s}), \\
\mathrm{CH}_{4}(\mathrm{~s})+(\mathrm{s}) \rightarrow \mathrm{CH}_{3}(\mathrm{~s})+\mathrm{H}(\mathrm{s}),
\end{gathered}
$$

or surface-oxygen attack as

$$
\mathrm{CH}_{4}(\mathrm{~s})+\mathrm{O}(\mathrm{s}) \rightarrow \mathrm{CH}_{3}(\mathrm{~s})+\mathrm{OH}(\mathrm{s}) \text {. }
$$

The gas-phase reaction and rate are known from combustion literature as [104, 119, 146-148].

$$
\mathrm{CH}_{4}+\mathrm{O}_{2} \rightarrow \mathrm{CH}_{3}+\mathrm{HO}_{2} \text {. }
$$

Experimental studies show that the $\mathrm{C}_{2}$ formation rates depend strongly on methyl-radical concentrations $[131,123,149,150]$. There is general agreement that the methyl radicals recombine in the gas-phase to form $\mathrm{C}_{2} \mathrm{H}_{6}$. Subsequent dehydrogenation of $\mathrm{C}_{2} \mathrm{H}_{6}$ produces $\mathrm{C}_{2} \mathrm{H}_{4}$. In high-temperature oxidative environments, the methane and $\mathrm{C}_{2}$ species can be easily oxidized to produce $\mathrm{CO}_{x}$ and $\mathrm{H}_{2} \mathrm{O}$, which is problematic 
Table 3: Global reactions in Oxidative Coupling of Methane as proposed by Staunch, et al. [108].

\begin{tabular}{ll}
\hline 1. & $\mathrm{CH}_{4}+2 \mathrm{O}_{2} \rightarrow \mathrm{CO}_{2}+2 \mathrm{H}_{2} \mathrm{O}$ \\
2. & $2 \mathrm{CH}_{4}+\frac{1}{2} \mathrm{O}_{2} \rightarrow \mathrm{C}_{2} \mathrm{H}_{6}+\mathrm{H}_{2} \mathrm{O}$ \\
3. & $\mathrm{CH}_{4}+\mathrm{O}_{2} \rightarrow \mathrm{CO}+\mathrm{H}_{2} \mathrm{O}+\mathrm{H}_{2}$ \\
4. & $\mathrm{CO}+\frac{1}{2} \mathrm{O}_{2} \rightarrow \mathrm{CO}_{2}$ \\
5. & $\mathrm{C}_{2} \mathrm{H}_{6}+\frac{1}{2} \mathrm{O}_{2} \rightarrow \mathrm{C}_{2} \mathrm{H}_{4}+\mathrm{H}_{2} \mathrm{O}$ \\
6. & $\mathrm{C}_{2} \mathrm{H}_{4}+2 \mathrm{O}_{2} \rightarrow 2 \mathrm{CO}+2 \mathrm{H}_{2} \mathrm{O}$ \\
7. & $\mathrm{C}_{2} \mathrm{H}_{6} \rightarrow \mathrm{C}_{2} \mathrm{H}_{4}+\mathrm{H}_{2}$ \\
8. & $\mathrm{C}_{2} \mathrm{H}_{4}+2 \mathrm{H}_{2} \mathrm{O} \rightarrow 2 \mathrm{CO}+4 \mathrm{H}_{2}$ \\
9. & $\mathrm{CO}+\mathrm{H}_{2} \mathrm{O} \rightarrow \mathrm{CO}_{2}+\mathrm{H}_{2}$ \\
10. & $\mathrm{CO}_{2}+\mathrm{H}_{2} \mathrm{O} \rightarrow \mathrm{CO}+\mathrm{H}_{2} \mathrm{O}$ \\
\hline
\end{tabular}

and needs to be avoided. The unwanted full oxidation proceeds on the catalyst with significant contributions from gas-phase reactions [105, 151, 107, 109].

Considering $\mathrm{La}_{2} \mathrm{O}_{3} / \mathrm{CaO}$ catalysts, Stansch et al. developed a global 10-step reaction mechanism (Table 3) [108]. Although the chemistry concerns heterogeneous catalysis, the reaction mechanism involves only gas-phase species. The paper reported empirical rate expressions for each of the reactions. Up to the present day, the Stansch et al. reaction mechanism is used widely in modeling studies of OCM processes [152154, 114].

Considering $\mathrm{Mn} / \mathrm{Na}_{2} \mathrm{WO}_{4} / \mathrm{SiO}_{2}$ catalysts, Ahari et al. [155] developed a microkinetic reaction mechanism that involves gas-phase and surface reactions. The surface reactions are represented as 11 irreversible steps. The gas-phase reactions are represented as 39 reversible steps among 13 species. The product gas-phase species include $\mathrm{CO}, \mathrm{CO}_{2}, \mathrm{H}_{2}, \mathrm{H}_{2} \mathrm{O}, \mathrm{C}_{2} \mathrm{H}_{4}$, and $\mathrm{C}_{2} \mathrm{H}_{6}$, but not higher hydrocarbons and aromatics. This reaction mechanism extends earlier studies by Marin and colleagues [105, 151].

There is clearly a need to develop and validate new reaction mechanisms that are catalyst specific and represent elementary reaction steps. Especially when surface-reaction steps are included, there is a need to evaluate thermodynamic properties of the surfaceadsorbed species. Although estimating or measuring such thermodynamic properties may be difficult, they play a central role in ensuring microscopic reversibility.

\section{OCM reactors}

Most laboratory-scale OCM reactors are implemented as catalytic packed beds within small-diameter tubes, such as illustrated in Fig. 14. Because the OCM process is highly exothermic, thermal control is important. Small-diameter tubes limit the radial temperature ${ }_{1052}$ varieties, but axial temperature variations can be sig- 1053 nificant. To avoid large axial temperature excursions, 1054

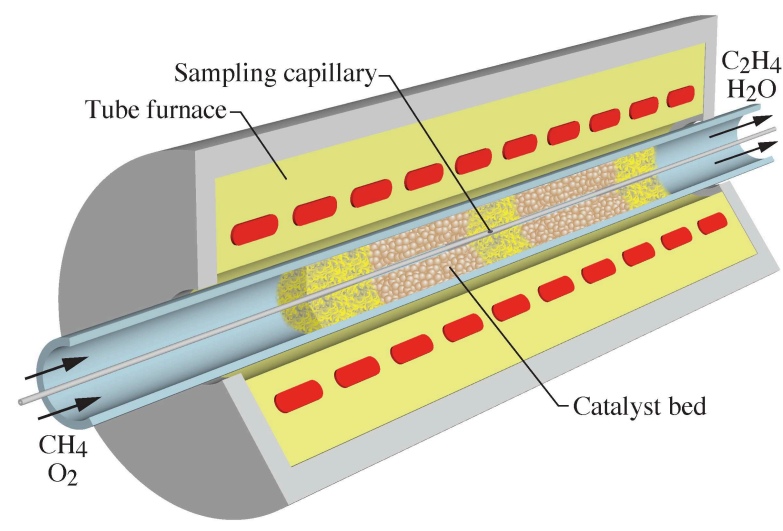

Figure 14: Laboratory-scale packed-bed reactor configuration modeled after Zohour et al. [113]. This experiment is configured with two separated catalyst beds and a central capillary tube for measuring gasphase species profiles. The catalysts are held in place by chemically inert glass-fiber packing.
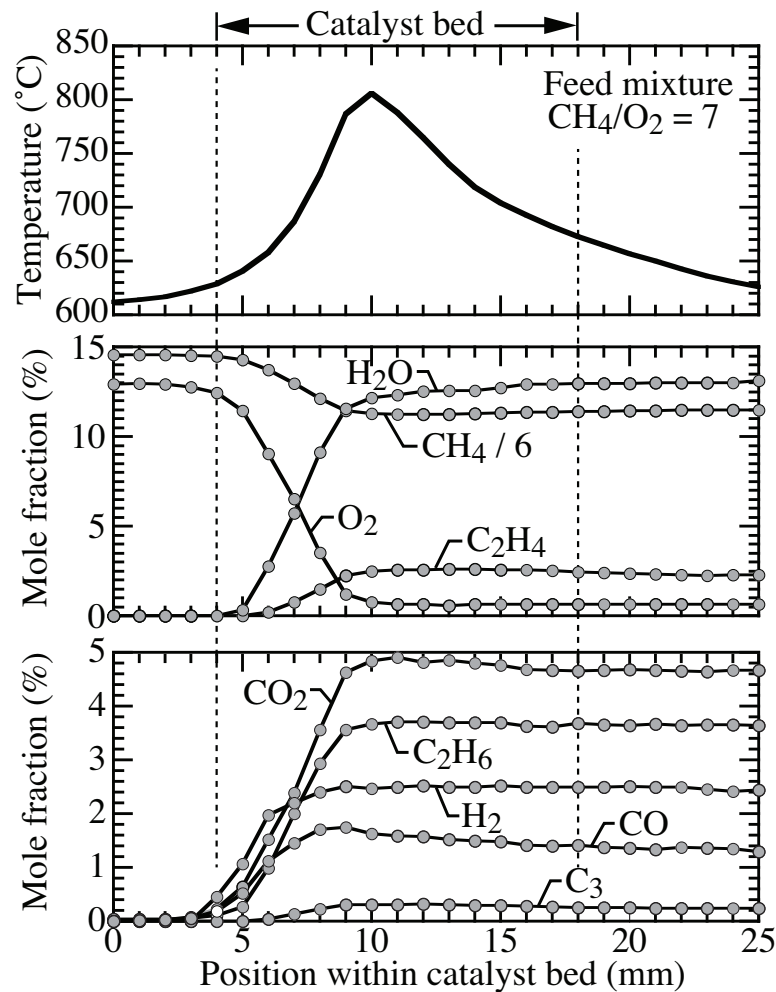

Figure 15: Measured temperature and species profiles from a packedbed experiment [156]. The feed mixture had a ratio of $\mathrm{CH}_{4} / \mathrm{O}_{2}=7$ and an inlet temperature of $600{ }^{\circ} \mathrm{C}$. The catalyst was $\mathrm{La}_{2} \mathrm{O}_{3}-\mathrm{CeO}_{2}$ in a nanofiber fabric configuration.

experiments are often run in dilute mixtures with low methane conversions. However, while useful in the laboratory setting, practical processes cannot be operated 
in dilute atmospheres. Typical experiments measure only the product species that leave the catalyst bed. An important aspect of the configuration shown in Fig. 14 is that species and temperature profiles can be resolved within the catalyst bed [157-159, 156, 113].

Figure 15 shows temperature and species profiles measured by Zohour et al. [156]. A mixture of methane and oxygen $\left(\mathrm{CH}_{4} / \mathrm{O}_{2}=7\right)$ enters the reactor at $600{ }^{\circ} \mathrm{C}$. Several very interesting observations emerge from these measurements. The reaction chemistry is essentially completed within about $5 \mathrm{~mm}$ of the gases first encountering the active catalyst material. The reaction heat associated with the rapid $\mathrm{O}_{2}$ consumption produces a rapid temperature rise of approximately $225^{\circ} \mathrm{C}$. The $\mathrm{O}_{2}$ is mostly consumed, with exhaust mole fraction being below $1 \%$. The major gas-phase products $\left(\mathrm{C}_{2} \mathrm{H}_{4}, \mathrm{C}_{2} \mathrm{H}_{6}\right.$, $\left.\mathrm{H}_{2} \mathrm{O}, \mathrm{CO}, \mathrm{CO}_{2}\right)$ are formed within the first $5 \mathrm{~mm}$ of ${ }^{1107}$ the $19 \mathrm{~mm}$ catalyst bed. Minor $\mathrm{C}_{3}$ products $\left(\mathrm{C}_{3} \mathrm{H}_{8}\right.$ and $\mathrm{C}_{3} \mathrm{H}_{6}$ ) were detected, but with mole fractions well be- ${ }^{1108}$ low $1 \%$. Following the initial reaction zone, the species ${ }_{1109}$ concentrations remain essentially unchanged until they 1110 exit the reactor. Although $\mathrm{H}_{2}$ measurements are usually 1111 not reported in the OCM literature, Fig. 15 shows signif- 1112 icant $\mathrm{H}_{2}$. Zohour et al. suggest that the significant levels 1113 of $\mathrm{H}_{2}$ may be due to surface reactions, such as are typi- 1114 cal in catalytic partial oxidation (CPOX) over Rh and Pt 1115 catalysts.

As is evident from the Zohour et al. measurements, 1117 OCM processes are characterized by a sharp local tem- 1118 perature rise (i.e., local hot spots). These measurements 1119 are consistent with other reported results [160-162]. 1120 However, the locally high temperatures apparently play ${ }_{1121}$ no beneficial role on the process. Actually, the high tem- 1122 perature plays a detrimental role in the sense that it con- ${ }_{1123}$ tributes to the production of unwanted total-oxidation ${ }_{1124}$ products (i.e., $\mathrm{H}_{2} \mathrm{O}$ and $\mathrm{CO}_{2}$ ). The appearance of total- 1125 oxidation products diminishes the yield of the desired ${ }_{1126}$ $\mathrm{C}_{2}$ products. Moreover, the downstream separation of ${ }_{1127}$ $\mathrm{CO}$ and $\mathrm{CO}_{2}$ from the $\mathrm{C}_{2}$ products is inefficient and ${ }_{1228}$ costly. The locally high temperatures contribute to other ${ }_{1129}$ undesired, or unsafe, conditions. Thermal runaway can ${ }_{1130}$ result from the gas-phase ignition of $\mathrm{CH}_{4}$ and the de- ${ }_{1131}$ sired $\mathrm{C}_{2}$ product stream. High temperatures also con- ${ }_{1132}$ tribute to catalyst degradation and deactivation. Main- ${ }_{1133}$ taining spatially uniform and relatively low temperature ${ }_{1134}$ beneficially affects OCM processes. Thus, as is also true ${ }_{1135}$ for other GTL processes, thermal control is important in ${ }_{1136}$ the design and development of high-performance reac- ${ }_{1137}$ tor technology.

In broad terms, thermal control in OCM reactors may 1139 follow three approaches. These include microchannel ${ }_{1140}$ reactors, membrane reactors, and staged reactors. Inno- 1141

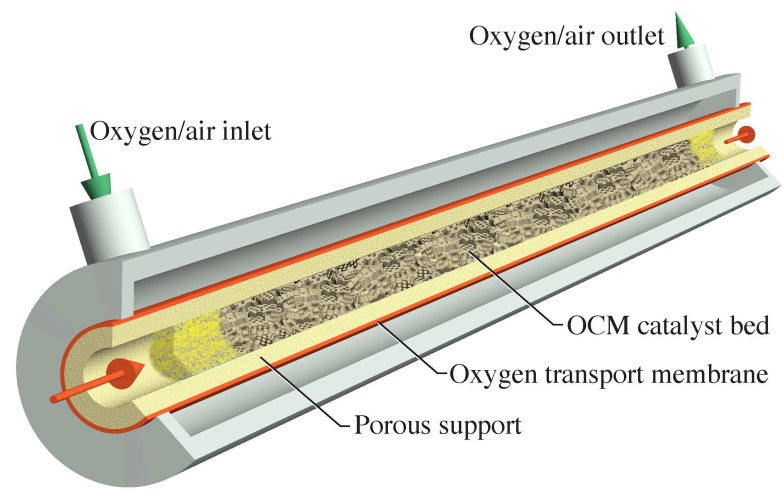

Figure 16: Illustration of an OCM reactor in a shell-and-tube configuration with an oxygen-permeable membrane.

vative designs may use combinations of the approaches.

\subsection{Microchannel reactors}

Microchannel reactors and integrated heat exchangers are known to be effective in controlling reaction temperature. Figure 12 illustrates a catalytic microchannelreactor design that is effective for Fischer-Tropsch synthesis. In this case the coolant is pressurized water, which is feasible for processes that require temperatures of around $300{ }^{\circ} \mathrm{C}$ and lower. For processes such as OCM that operate at temperatures around $600{ }^{\circ} \mathrm{C}$ and higher, pressurized water is not an option. Finding a suitable non-reactive high-capacity heat-transfer fluid is challenging, if possible. At these temperatures, the coolant must be a gas.

Chemically inert channels with flowing gases can help to control temperature on the adjacent catalyst beds. However, gases have limited capacity to accept high heat loads and maintain small temperature increases. An alternative is to develop a reactor such as the one shown in Fig. 6, where both sets of microchannels are catalytically active. In this case, the exothermic heat from the OCM process is accepted by an endothermic process within the mating channels.

High-performance catalytic microchannel reactors must accommodate some practical considerations. The thermal demands of the endothermic and exothermic processes must be roughly balanced. Assuming that OCM is the target process, to be economic the endothermic process must also deliver some valuable product in addition to simply controlling temperature for the OCM process. An endothermic steam or dry reforming process would represent one potentially viable option.

In addition to balancing the overall exothermicity and endothermicity, designing a high-performance catalytic microchannel reactor must consider the spatial locations 
of the exothermic and endothermic chemistry. As may be noted from Fig. 15, the OCM exothermic heat release can be highly localized. It may be difficult to find a mating endothermic process that is also localized and occurs at the appropriate location within the reactor.

\subsection{Membrane reactors}

In reactors such as the one illustrated by Fig. 14, premixed methane and oxygen enter the catalyst bed together. One of the reasons for the localized heat release is that all of the available $\mathrm{O}_{2}$ can be consumed rapidly (Fig. 15). If the oxygen were added in a distributed manner along the length of the reactor, the local temperature spikes could be significantly diminished.

Figure 16 illustrates a permselective oxygen membrane reactor [163]. The membranes may take alterna- ${ }^{1193}$ tive forms. Oxide-ion conducting membranes are typ- ${ }^{1194}$ ically dense ceramics that are mixed ionic-electronic ${ }^{1195}$ conductors (MIEC). A doped perovskite, particularly ${ }^{1196}$ $\mathrm{La}_{x} \mathrm{Ca}_{1-x} \mathrm{FeO}_{3-\delta}$ (LCF), is a good candidate because it ${ }^{1197}$ is stable in both oxidizing and reducing environments ${ }^{1198}$ and has reasonably good oxide-ion conductivity [164- 1199 169]. Because the ion conductivity of these materials is 1200 activated (in the range of $75 \mathrm{~kJ} \mathrm{~mol}^{-1}$ ), elevated temper- ${ }^{1201}$ ature is needed to achieve good oxygen fluxes. Practi- ${ }^{1202}$ cal operating temperatures around $600{ }^{\circ} \mathrm{C}$ and above are ${ }^{1203}$ compatible with OCM processes.

To avoid costly downstream separations, practical ${ }^{1204}$ OCM processes need pure oxygen, not air. Materials 1205 such as LCF conduct only oxide ions (and electronic 1206 charge carriers). Thus, in a reactor such as illustrated in 1207 Fig. 16, the outer shell can be fed with air. The mem- ${ }_{1208}$ brane accomplishes in-situ air separation, avoiding the ${ }_{1209}$ need for an upstream air-separation process. Such pro- 1210 cess intensification (i.e., combining two otherwise sep- 1211 arate unit processes) can be beneficial.

Although the MIEC ceramics are oxide-ion conduc- 1213 tors, the ion conductivity is not high. To achieve prac- 1214 tical oxygen fluxes, the membranes must be thin (order 1215 tens of microns). Such thin membranes must be sup- 1216 ported on compatible porous-ceramic supports.

1217

Another membrane approach is based on so-called 1218 hollow-fiber tubes [170-175]. These tubes, which ${ }_{1219}$ are fabricated from mixed-conducting ceramics using a 1220 phase-inversion technique, have a very interesting archi- 1221 tecture $[171,176]$. Conically shaped "microchannels" ${ }_{1222}$ emanate radially from the inside of the tube toward the ${ }_{1223}$ exterior surface. The diameters of the radial microchan- ${ }_{1224}$ nels are relatively large at the tube's inner surface and ${ }_{1225}$ decrease radially, with the tube's exterior surface being 1226 a dense membrane. In some cases, a catalyst coating 1227 can be deposited within the radial channels.

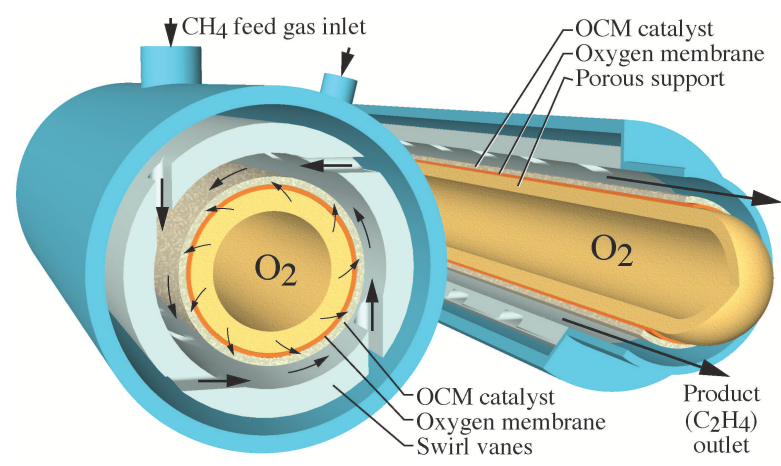

Figure 17: Possible configuration of a swirling tubular membrane reactor.

Yet another membrane approach depends on nanoporous ceramic (e.g., $\mathrm{Al}_{2} \mathrm{O}_{3}$ ) structures [177-181]. The oxygen fluxes can be much high than those in the dense-ceramic MIEC materials. Porous ceramics are much less costly than dense ceramic ion-transport membranes. However, upstream air separation is needed to produce the pure oxygen. Also, porous membranes can permit diffusion of hydrocarbons from the catalyst bed to the oxygen shell gas. Such reactors are usually operated with high oxygen pressure on the shell side (e.g., 6 bar) to prevent the deleterious back diffusion.

\subsection{Tubular-swirl reactors}

Even with a membrane reactor such as illustrated in Fig. 16, axial variation in temperature and composition must be expected. Introducing the oxygen in a spatially distributed manner via the membrane diminishes the axial variations, but does not eliminate them [112]. As illustrated in Fig. 17, a swirling tubular membrane configuration forms the basis for a potentially interesting reactor design.

In 1985, Ishizuka first introduced the concept of swirling tubular flames and demonstrated the axial independence of the flow field [182]. Shortly thereafter, Takeno and Ishizuka then developed the similarity analysis showing the axial independence in a mathematical setting [183]. Since that time, a significant body of literature documents the flow behavior in both premixed and non-premixed settings. Ishizuka wrote an extensive review in 1993 [184]. The recent book edited by Ishizuka and Dunn-Rankin documents the fundamental and practical state of the art up to 2013 [185].

The swirling tubular flow is analogous to the similarity behavior of the much-better-known stagnation flows that are widely used in fundamental flame studies [43]. In an ideal axisymmetric stagnation flow (e.g., Fig. 18), the temperature and concentration fields are functions 


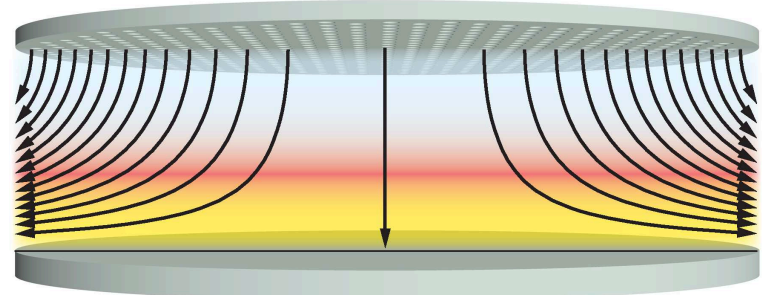

Figure 18: Cartoon image of an axisymmetric planar stagnation flow, illustrating radial independence of the temperature and concentration fields.

of the axial position and independent of the radial posi- ${ }_{1280}$ tion. In an ideal swirling tubular flow, the temperature ${ }_{1281}$ and concentration fields are functions of the radial po- ${ }_{1282}$ sition and independent of the axial position. Thus, in ${ }_{1283}$ a configuration such as the one shown in Fig. 17 the ${ }_{1284}$ chemistry performance will be essentially independent ${ }_{1285}$ of the axial position within the reactor.

As illustrated in Fig. 17, an oxygen-permeable mem- ${ }_{1287}$ brane is supported on the exterior surface of an inner ${ }_{1288}$ porous tube. A porous OCM catalyst layer is deposited ${ }_{1289}$ onto the exterior surface of the membrane. The methane ${ }_{1290}$ feed is introduced into the annular reaction volume via ${ }_{1291}$ swirl vanes [186]. The reaction products exit axially. ${ }_{1292}$ Based on the tubular similarity, and neglecting some in- ${ }_{1293}$ evitable end effects, the temperature and composition ${ }_{1294}$ profiles within the annular reaction zone should be es- ${ }_{1295}$ sentially independent of the axial position. Thus, unlike a typical membrane reactor (e.g., Fig. 16) the oxygen flux and the reaction chemistry should be uniform ${ }_{1298}$ through the reactor.

Based on numerous tubular flame studies, there is ${ }_{1300}$ good reason to expect that a tubular swirl reactor should ${ }_{1301}$ perform well. However, the present paper is the first to ${ }_{1302}$ suggest such an approach. Reactors of this type have ${ }_{1303}$ not yet been designed or tested.

\subsection{Segmented reactors}

Figure 19 illustrates a process and reactor configura- ${ }_{1307}$ tion that integrates two unit processes. As illustrated, ${ }_{1308}$ the system combines an exothermic OCM process with 1309 an endothermic steam-reforming process. However, the 1310 approach is significantly different from the approach as ${ }_{1311}$ represented by the microchannel reactor illustrated in ${ }_{1312}$ Fig. 6. In Fig. 19 two processes are running in paral- 1313 lel, with the catalytic processes confined to relatively 1314 small, insulated, reaction chambers. The exothermic 1315 OCM process heats the reactive gases and the catalyst 1316 bed. The endothermic SRM process cools the reactive ${ }_{1317}$ gases and the catalyst bed. The heated gases from the 1318
OCM reactors and the cooled gases from the SRM reactors enter a counter-flow microchannel heat exchanger. The role of the heat exchanger is to heat the cool gases and cool the hot gases. The partially reacted output streams from the heat exchangers are directed to the next set of reactors. Oxygen (or steam) can be added between the reactor stages. The two gas streams remain separated throughout the process in the sense that the OCM stream never mixes with the SRM stream. After a series of reactor-heat-exchanger sets, two final product streams emerge.

This segmented-reactor approach is motivated by Mleczko and colleagues [187, 86], who introduced such a novel multi-bed reactor that integrates OCM and methane dry reforming (DRM). The approach enables good oxygen control and thermal control, and hence process performance. In this sense, despite the separated catalytic reactors and heat exchangers, the overall process is "intensified."

The segmented OCM process behaves as a discrete implementation of a membrane reactor (e.g., Fig. 16). In the membrane reactor the oxygen is transferred through the membrane along the entire length of the reactor. In the segmented approach, the oxygen is added between stages. The membrane is passive in the sense that the local oxygen flux depends on the local oxygen partial pressures across the membrane. In the segmented approach, the oxygen addition can be actively controlled at each injection point. A number of studies have addressed the beneficial role of multi-stage $\mathrm{O}_{2}$ feed in OCM [119, 113, 188-190].

Zohour et al. [113] reported interesting OCM experiments in a reactor such as the one illustrated Fig. 14. In these experiments the catalyst bed was separated into two sections. Although not illustrated in Fig. 14, the experiments introduced oxygen separately just upstream of both catalyst sections. Compared to an experiment that introduced all the oxygen together with the methane at the entrance of the catalyst bed, the two-point injection produced better results. With all the oxygen introduced with the methane, Fig. 15 shows a significant and rapid temperature increase. With only a portion of the oxygen introduced in the first bed, Zohour et al. reported a significantly lower temperature rise. Upon introduction of oxygen into the second catalyst bed, the temperature again increases, but less than it did in the first bed. Because the process using two catalyst beds and segmented oxygen addition reduced the temperature excursions, the process was overall more efficient than the single-bed process.

The segmented approach represented by Fig. 19 shares some similarities with compressor intercooling 


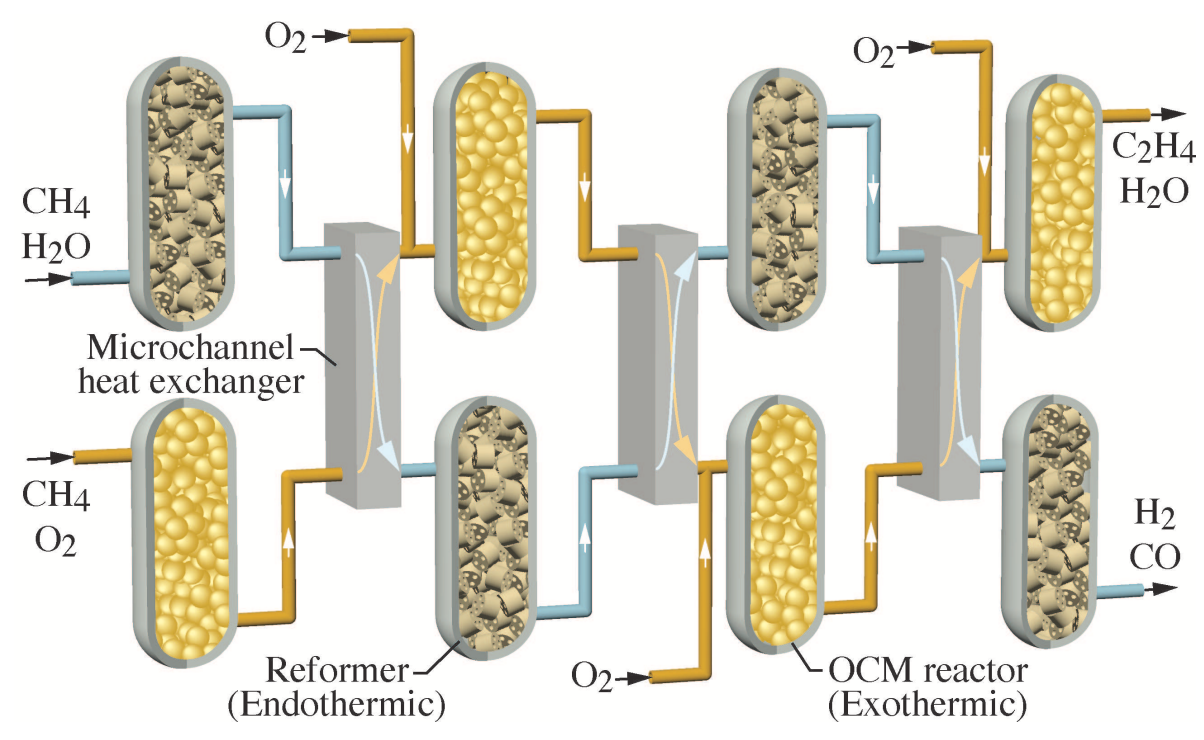

Figure 19: Illustration of a staged segmented process, combining an exothermic OCM process with an endothermic SRM process.

and segmented combustion in gas-turbine engines [191, ${ }_{1346}$ 192]. As shown by Ramakrishnan and Edwards [191], ${ }_{1347}$ dividing an overall process into smaller segments can 1348 improve thermodynamic efficiency by limiting temper- 1349 ature excursions. Sirignano, et al. [193] explored simi- 1350 lar interturbine-burner (ITB) concepts to distribute the ${ }_{1351}$ combustion between gas-turbine stages and improve ${ }_{1352}$ overall efficiency. Of course, there are also prices to ${ }_{1353}$ be paid for adding complexity and increasing parasitic ${ }_{1354}$ losses such as pressure drop.

1355

Although certainly not proven, there are reasons to 1356 expect that novel designs such as in Fig. 19 might prove 1357 beneficial. In addition to the consideration of chemical 1358 and thermodynamic performance and parasitic losses, 1359 practical reactor development must also be concerned 1360 with operational and maintenance costs. Essentially all high-temperature hydrocarbon-processing catalysts suffer degradation and deactivation over time. Thus, the regeneration and/or replacement of deactivated catalysts could be easier and less costly if the catalysts were housed on small detachable vessels such as illustrated in Fig. 19.

\section{Methane dehydroaromatization}

Methane Dehydroaromatization (MDA) is a process that is intended to produce benzene from methane [194- ${ }_{1371}$ $197,8]$. In gross global terms, MDA may be represented ${ }_{1372}$ as

$$
6 \mathrm{CH}_{4} \rightleftharpoons \mathrm{C}_{6} \mathrm{H}_{6}+9 \mathrm{H}_{2}
$$

The MDA chemistry is quite different from the OCM chemistry. The MDA process is usually implemented with a bi-functional catalyst such as Mo/ZSM and operated at temperatures around $800{ }^{\circ} \mathrm{C}[40,41]$. The methane is activated on the Mo sites, primarily producing ethylene and hydrogen. The ethylene can subsequently react at the zeolite Brønsted-acid sites which initiate a series of hydrogenation, dehydrogenation, oligomerization, $\beta$-scission, and cyclization reactions, producing cyclohexane and ultimately the desired benzene.

Unfortunately, the process does not automatically terminate at benzene, but continues to produce naphthalene and higher aromatics. For example, the competing naphthalene $\left(\mathrm{C}_{10} \mathrm{H}_{8}\right)$ production,

$$
10 \mathrm{CH}_{4} \rightleftharpoons \mathrm{C}_{10} \mathrm{H}_{8}+16 \mathrm{H}_{2} .
$$

decreases the desired benzene yield. Additionally, naphthalene contributes to carbon deposits and catalyst deactivation via the subsequent formation of higher polyaromatic hydrocarbons (PAH). Equation 23 is qualitatively instructive, but much too simplified to predict actual MDA performance that includes significant production of unwanted side products. Karakaya et al. [41] have developed a 50-step reaction mechanism to describe the MDA process up through naphthalene formation.

As is evident from the global reaction, a great deal of $\mathrm{H}_{2}$ is produced, which causes a significant equilibrium limitation on the methane conversion and benzene yield. Based on the thermodynamics of Reaction 23, the 


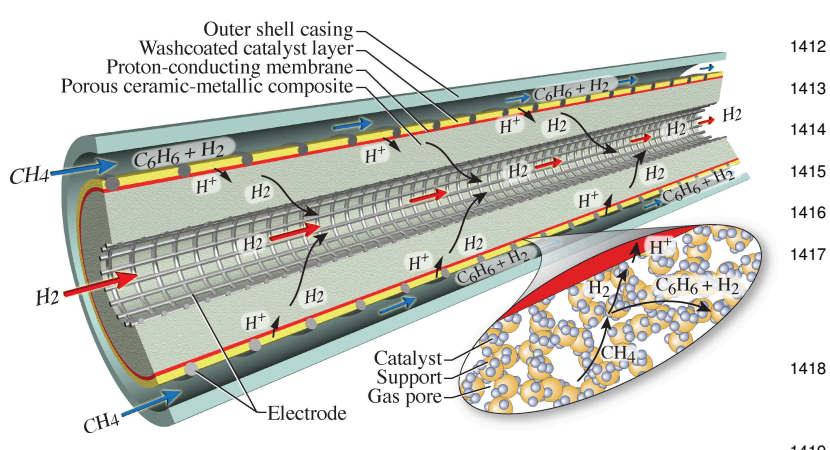

Figure 20: Illustration of a shell-and-tube MDA reactor with a polar- 1420 ized proton-conducting membrane.

equilibrium methane conversion is typically around 10$12 \%$ at $700{ }^{\circ} \mathrm{C}$. As with the methane reforming or OCM, MDA processes may also be able to benefit from novel reactor design and process intensification. For example, a hydrogen-permeable membrane that removes $\mathrm{H}_{2}$ from the catalyst bed would increase methane conversion and may improve benzene yield [198, 199].

Figure 20 illustrates aspects of a possible MDA reactor in a shell-and-tube configuration with a polarized proton-conducting membrane. Methane is introduced on the shell side where it reacts on a catalyst washcoat, producing hydrogen, benzene, and a range of other side 1433 products. The role of the membrane is to remove $\mathrm{H}_{2},{ }_{1434}$ enabling further conversion of the $\mathrm{CH}_{4}$. Assuming a 1435 pure hydrogen-permeable membrane, the separated hy- 1436 drogen is itself a valuable product.

1437

As discussed in the following section, there are two ${ }^{1438}$ types of high-temperature hydrogen-permeable mem- 1439 branes. One is based on palladium or palladium al- ${ }^{1440}$ loys [200]. The other is based on dense ceramic ${ }^{1441}$ perovskites such as doped barium zirconates (e.g., ${ }^{1442}$ $\mathrm{BaZr}_{0.9} \mathrm{Y}_{0.1} \mathrm{O}_{3-\delta}$, BZY10), which are mixed ionic- ${ }^{1443}$ electronic conductors [201-204].

The proton flux generally follows a Nernst-Planck re- ${ }^{1445}$ lationship, which depends on gradients of defect con- ${ }^{1446}$ centration and electrostatic potential [204]. Although ${ }^{1447}$ these ceramic membranes are proton conductors, the ion ${ }^{1448}$ conductivity is relatively low. Because the electronic ${ }^{1449}$ conductivity is also very low, it is possible to establish ${ }^{1450}$ an electrostatic potential across the membrane, which ${ }^{1451}$ can increase the proton flux by increasing the protonic ${ }^{1452}$ migration. Although the electrode fabrication and at- ${ }^{1453}$ tachment can be challenging, it is possible to control ${ }^{1454}$ the hydrogen flux via electrical polarization [201].

The removal of hydrogen (e.g., via a membrane) tends to favor naphthalene production over benzene production. Thus, although $\mathrm{H}_{2}$ membranes promote in- creased methane conversion, benzene yield may not be improved. Interventions, such as low-level steam addition, may assist in depressing the carbon deposition [205, 206]. However, the MDA process must overcome significant challenges to become practically viable.

\section{Membrane technology}

Membranes for gas-to-liquids applications must be stable at high temperature, which effectively eliminates polymer materials. Hydrogen-permeable membranes can be fabricated from palladium and palladium alloys [207, 200]. Some dense perovskite ceramics, such as doped barium zirconates, are proton conductors that enable hydrogen permselectivity [208-211]. Practical oxygen-permeable membranes are all fabricated from ceramics, but can take alternative forms that include porous structures, mixed ionic-electronic conductors (MIEC), and nearly pure oxide-ion conductors. The ceramic ion conductors are based on heterovalently doped polycrystalline materials [2].

\subsection{Oxygen-transport membranes}

Mixed-conducting oxygen-transport membranes are typically doped perovskites such as $\mathrm{La}_{1-x} \mathrm{Ca}_{x} \mathrm{FeO}_{3-\delta}$ (LCF). These materials conduct oxide ions with internal charge compensation relying on the formation and transport of small-polaron electronic defects [167, 212]. In addition to oxide-ion conductivity, these materials also have relatively high electronic conductivity. For applications such as reformers or OCM, one side of the membrane is exposed to air (i.e., oxidizing) but the other side is exposed to hydrocarbons (i.e., reducing). The LCF material is particularly appropriate because it is stable in both oxidizing and reducing environments [164, 213, 167, 169, 214]. Many of the otherwise good MIEC oxide-ion conductors, such as $\mathrm{La}_{1-x} \mathrm{Sr}_{x} \mathrm{Co}_{1-y} \mathrm{Fe}_{y} \mathrm{O}_{3-\delta}$ (LSCF), are stable only in oxidizing environments.

Oxygen transport through the membrane depends on the reaction of molecular oxygen on one membrane surface to fill an oxygen vacancy within the membrane crystal lattice, and the reverse reaction at the opposite surface to release $\mathrm{O}_{2}$ into the gas phase. Written in Kröger-Vink notation, the "incorporation" and "disproportionation" reactions at the membrane surfaces may be represented as

$$
\frac{1}{2} \mathrm{O}_{2}+\mathrm{V}_{\mathrm{O}}^{\bullet \bullet}+2 \mathrm{Fe}_{\mathrm{Fe}}^{\times} \rightleftharpoons \mathrm{O}_{\mathrm{O}}^{\times}+2 \mathrm{Fe}_{\mathrm{Fe}}^{\bullet} .
$$




$$
2 \mathrm{Fe}_{\mathrm{Fe}}^{\times} \rightleftharpoons \mathrm{Fe}_{\mathrm{Fe}}^{\prime}+\mathrm{Fe}_{\mathrm{Fe}}^{\bullet},
$$

Reactions 25 and 26 involve three mobile charged defects. They are the oxygen-ion vacancies $\mathrm{V}_{\mathrm{O}}^{\bullet \bullet}$, the reduced iron small polaron $\mathrm{Fe}_{\mathrm{Fe}}^{\prime}$, and the oxidized iron small polaron $\mathrm{Fe}_{\mathrm{Fe}}^{\bullet}$. In the Kröger-Vink notation the superscript "•" indicates a defect with a positive charge, the "," indicates a defect with negative charge, and the " $x$ " indicates charge neutrality. The subscripts indicate the "site" where the defect is localized. The disproportionation reaction is the result of the possibility that $\mathrm{Fe}^{2+}, \mathrm{Fe}^{3+}$, and $\mathrm{Fe}^{4+}$ can all be present simultaneously [167].

The defect concentrations are governed by conservation equations as

$$
\frac{\partial\left[X_{k}\right]}{\partial t}+\nabla \cdot \mathbf{J}_{k}=0
$$

where $\left[X_{k}\right]$ are defect concentrations and $\mathbf{J}_{k}$ are the 1498 Nernst-Planck defect fluxes. Assuming dilute transport, 1499 the Nernst-Planck relationship may be written as

$$
\mathbf{J}_{k}=-D_{k}\left(\nabla\left[X_{k}\right]+\frac{z_{k} F}{R T}\left[X_{k}\right] \nabla \Phi_{\mathrm{e}}\right),
$$

where $D_{k}$ are defect diffusion coefficients, $z_{k}$ are the de- ${ }^{1504}$ fect charges, $R$ is the gas constant, $F$ is the Faraday con- ${ }^{1505}$ stant, and $\Phi_{\mathrm{e}}$ is the electrostatic potential. The electro- ${ }^{1506}$ static potential must be established to effectively main- ${ }^{1507}$ tain electroneutrality, which can be represented in terms ${ }^{1508}$ of the Gauss law as

$$
\nabla \cdot(\varepsilon \nabla \Phi)=-\rho_{\mathrm{e}}=-\sum_{k=1}^{K} F z_{k}\left[X_{k}\right],
$$

where $\varepsilon$ is the dielectric constant and the local charge ${ }^{1514}$ density is represented as $\rho_{\mathrm{e}}$. Additionally, the reaction ${ }^{1515}$ chemistry and transport must respect site constraints. The defect transport within the ceramic MIEC materi- ${ }^{1516}$ als is activated, with activation energies usually in the ${ }_{1517}$ range of $75 \mathrm{~kJ} \mathrm{~mol}^{-1}$. Thus, the net oxygen flux depends ${ }_{1518}$ greatly on the operating temperature. Details for model- ${ }_{1519}$ ing the incorporation chemistry and the defect transport ${ }_{1520}$ within the membrane may be found in previous publi- ${ }_{1521}$ cations [201-204].

Although materials such as LCF are certainly viable, oxide-ion conductors such as doped ceria or doped zirconia are oxide-ion conductors and are usually more stable than the perovskite oxide-ion membranes. The ceria ${ }^{1523}$ and zirconia materials have good oxide-ion conduction but very low electronic conduction. Because of the low ${ }_{1524}$ electronic conductivity, the membrane can be polarized ${ }_{1525}$

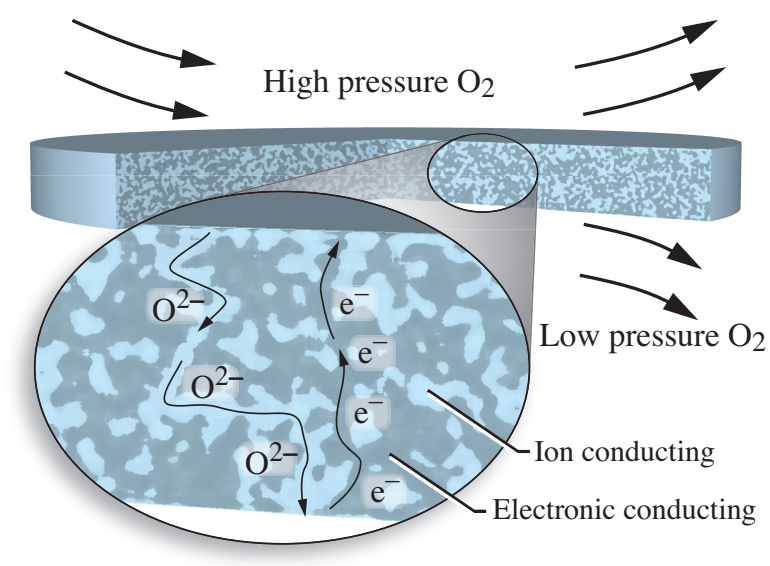

Figure 21: Illustration of dual-phase oxygen-ion conducting membrane.

in the sense that an electric potential can be maintained across the membrane. This property enables electrochemical membrane applications such as in solid-oxide fuel cells. As can be seen from Eq. 28 the defect flux depends on the electrostatic-potential gradient. Thus, there may be benefits to polarizing the membrane in the sense that an applied electric field can be used to control the oxide-ion fluxes.

Without imposed polarization, oxide-ion flux through the the ceria and zirconia materials is greatly limited by the electronic conduction. Dual phase membranes provide a means to incorporate highly stable ceramics and also deliver good oxygen fluxes [215-219]. As illustrated in Fig. 21, a dual-phase membrane is typically a ceramic-ceramic composite that is composed of one phase that is dominantly an electron conductor (e.g., strontium-doped lanthanum chromate LSCr) and the other phase that is dominantly an oxide-ion conductor (e.g., yttria-doped zirconia, YSZ) [218].

\subsection{Hydrogen-transport membranes}

Materials such as doped barium zirconates (e.g., $\left.\mathrm{BaZr}_{0.9} \mathrm{Y}_{0.1} \mathrm{O}_{3-\delta}, \mathrm{BZY} 10\right)$ are MIECs that are proton conductors, and hence can operate as permselective hydrogen membranes. The incorporation reactions may be written as

$$
\begin{gathered}
\frac{1}{2} \mathrm{H}_{2}+\mathrm{O}_{\mathrm{O}}^{\bullet} \rightleftharpoons \mathrm{OH}_{\mathrm{O}}^{\bullet}, \\
\frac{1}{2} \mathrm{O}_{2}+\mathrm{O}_{\mathrm{O}}^{\times}+\mathrm{V}_{\mathrm{O}}^{\bullet \bullet} \rightleftharpoons 2 \mathrm{O}_{\mathrm{O}}^{\bullet}, \\
\mathrm{H}_{2} \mathrm{O}+\mathrm{V}_{\mathrm{O}}^{\bullet \bullet}+\mathrm{O}_{\mathrm{O}}^{\times} \rightleftharpoons 2 \mathrm{OH}_{\mathrm{O}}^{\bullet} .
\end{gathered}
$$

The mobile charged defects are protons $\left(\mathrm{OH}_{\mathrm{O}}^{\bullet}\right)$, oxygen vacancies $\left(\mathrm{V}_{\mathrm{O}}^{\bullet \bullet}\right)$, O-site polarons $\left(\mathrm{O}_{\mathrm{O}}^{\bullet}\right)$ [203]. The 
protonic ceramics do not behave as pure hydrogen- 1570 transport membranes. These materials also conduct ox- 1571 ide ions as as well as small polarons. Thus, depending 1572 on the gas-phase conditions across the membranes, the 1573 materials enable the defacto simultaneous transport of 1574 $\mathrm{H}_{2}, \mathrm{O}_{2}$, and $\mathrm{H}_{2} \mathrm{O}$. Depending on the application, such 1575 membrane behavior may be beneficial, or not.

\subsection{Palladium membranes}

Palladium is a well known and well studied hydro- 1579 gen membrane material [207, 200]. The hydrogen molar 1580 flux through the Pd membrane generally follow Sieverts ${ }_{1581}$ law as

$$
\mathbf{J}_{\mathrm{H}_{2}}^{\mathrm{M}}=k_{\mathrm{Pd}} \frac{p_{\mathrm{H}_{2}, \mathrm{I}}^{n}-p_{\mathrm{H}_{2}, \mathrm{II}}^{n}}{L_{\mathrm{Pd}}},
$$

where $L_{\mathrm{Pd}}$ is the membrane thickness and the local hy- 1585 drogen partial pressures across the membrane are rep- ${ }^{1586}$ resented as $p_{\mathrm{H}_{2}, \mathrm{I}}$ and $p_{\mathrm{H}_{2}, \mathrm{II}}$, respectively. The expo- ${ }^{1587}$ nent $n \approx 0.5$ can depend on the hydrogen incorporation ${ }^{1588}$ chemistry. The hydrogen permeability can be expressed 1589 in the Arrhenius form as

$$
k_{\mathrm{Pd}}=k_{\mathrm{Pd}}^{\circ} \exp \left(-\frac{E_{\mathrm{a}}}{R T}\right),
$$

where $E_{\mathrm{a}}$ is an activation energy.

\section{Summary and conclusions}

As a clean-burning fuel, natural-gas combustion will 1598 surely continue to play a major role in the energy land- 1599 scape. One can expect continuing progress in the de- 1600 velopment of advanced combustion technology, further ${ }_{1601}$ increasing combustion efficiency and reducing environ- 1602 mental impact. At the same time, natural gas is poised ${ }_{1003}$ to play increasingly important roles in the production of logistics fuels and commodity chemicals.

The large-scale reforming of natural gas is the primary route for hydrogen production, which is central 1605 to a wide variety of products that include petroleum 1606 refining, ammonia synthesis, and polymer processing. 1607 The annual production of $\mathrm{H}_{2}$ exceeds 50 million met- 1608 ric tons. In the future, many predict a "hydrogen econ- 1609 omy," which could include fuel cells and hydrogen com- 1610 bustion. Although reforming processes are technolog- 1611 ically mature and commercially practiced on a very 1612 large scale, there are significant opportunities for im- 1613 provement. For example, process intensification via integrated microchannel reactors and heat exchangers is ${ }_{1614}$ maturing rapidly, reducing capital cost and improving process efficiency. New hydrogen permselective mem- 1615 branes are likely to play important roles in improving ${ }_{1616}$ the reforming and separation processes.
Fischer-Tropsch synthesis provides a commercially viable means to transform synthesis gas to refinery feedstocks. The synthesis gas is mostly produced via natural-gas reforming. Substantial research and development efforts are focused on innovative approaches for improving these processes. For example, microchannel reactor technology is likely to replace large-scale fixedbed and slurry-bubble reactors.

Remote or stranded gas is a potentially valuable resource and also a source of environmentally harmful greenhouse-gas emissions. The development of practical, cost-effective, small-scale gas-to-liquids technology is necessary for the beneficial exploitation of these resources. Compared to refinery-scale processes, novel reactor technology based on process intensification concepts will surely be needed.

Processes such as oxidative coupling of methane (OCM) have been known for years and laboratory-scale research continues to be active. Such direct routes are potentially more efficient than first producing syngas and subsequently transforming to desired product streams. However, the eventual success of such processes will almost certainly depend on advanced catalysts and novel reactor technologies.

Based on new and innovative concepts that are being developed and demonstrated at the laboratory and pilot scales, there is ample reason to expect the growth and maturation of new commercially viable gas-to-chemicals technology. Process intensified approaches, including the combination of nanostructured catalysts, microchannel reactors, permselective membranes, closely coupled processes, and thermal control, will surely contribute to significant advances in critically needed technologies.

\section{Acknowledgements}

This work was supported by the Office of Naval Research (N00014-08-1-0539), the Air Force Office of Scientific Research (FA9550-12-1-0495), and CoorsTek, Inc. We gratefully acknowledge the frequent and insightful discussions with Profs. Greg Jackson, Robert Braun, Sandrine Ricote, Ryan O'Hayre, Brian Trewyn, Douglas Way, and Anthony Dean (CSM) and Drs. Grover Coors and Jim Steppan (CoorsTek, Membrane Sciences).

\section{References}

\section{References}

[1] J.H. Lunsford. Catalytic conversion of methane to more useful chemicals and fuels: A challange for the 21st century. Catal. 
Today, 63:165-174, 2000 .

[2] K. Li. Ceramic Membranes for Separation and Reaction. Wi- 1684 ley, Hoboken, NJ, 2007.

[3] K. Aasberg-Petersen, I. Dybkjaer, C.V. Ovesen, N.C. Schjødt, 1686 J. Sehested, and S.G. Thomsen. Natural gas to synthesis gas: 1687 Catalysts and catalytic processes. J. Nat. Gas Sci. Eng., 3:423- 1688 459, 2011

[4] A. de Klerk and D.L. King, editors. Synthetic Liquids Produc- 1690 tion and Refining. ACS Symposium Series. American Chemi- 1691 cal Society, Washington, DC, 2011.

[5] J.R. Rostrup-Nielsen and L.J. Christiansen. Concepts in Syn- 1693 gas Manufacture, volume 10 of Catalytic Science Series. Im- 1694 perial College Press, London, 2011.

[6] P.M. Maitlis and A. de Klerk, editors. Greener Fischer-Tropsch 1696 Processes for Fuels and Feedstocks. Wiley-VCH, Weinheim, 1697 Germany, 2013.

[7] D.A. Wood, C. Nwaoha, and B.F. Towler. Gas-to-liquids 1699 (GTL): A review of an industry offering several routes for mon- 1700 etizing natural gas. J. Nat. Gas Sci. and Eng., 9:196-208, 2012. 170

[8] J.J. Spivey and G. Hutchings. Catalytic aromatization of 1702 methane. Chem. Soc. Rev., 43:792-803, 2014.

[9] D.A. Wood. Catalytic conversion of natural gas and methane to 1704 synthesis gas and beyond: A collection of published research 1705 (2009-2015). J. Nat. Gas Sci. Eng., 26:737-745, 2015.

[10] F. Gallucci and M. van Sint Annaland, editors. Process In- 1707 tensification for Sustainable Energy Conversion. Wiley, West 1708 Sussex, UK, 2015.

[11] A. de Klerk. Fischer-Tropsch refining. Wiley-VCH, Wein- 1710 heim, Germany, 2011.

[12] G.A. Olah, A. Goeppert, and G.K.S. Prakash. Beyond Oil and 1712 Gas: The Methanol Economy. Wiley-VCH, Weinheim, Ger- 1713 many, 2006.

[13] P.M. Maitlis and A. de Klerk. New directions, challenges, and 1715 opportunities. In P.M. Maitlis and A. de Klerk, editors, Greener 1716 Fischer-Tropsch Processes for Fuels and Feedstocks. Wiley- 1717 VCH, Weinheim, Germany, 2013.

[14] M. Crow, B. Bozeman, W. Meyer, and Jr. R. Shangraw Syn- 1719 thetic Fuel Technology Development in the United States: A 1720 Retrospective Assessment. Praeger, New York, 1988.

[15] R.J. Kee, H. Zhu, and D.G. Goodwin. Solid-oxide fuel cells 1722 with hydrocarbon fuels. Proc. Combust. Inst., 30:2379-2404, 1723 2005.

[16] J.R. Rostrup-Nielsen. Steam reforming of hydrocarbons. A 1725 historical perspective. Stud. Surf. Sci. Catal., 147:121-126, 1726 2004.

[17] J.R. Rostrup-Nielsen, J. Sehested, and J.K. Nørskov. Hydrogen 1728 and synthesis gas by steam and $\mathrm{CO}_{2}$ reforming. Adv. Catal., 1729 47:65-139, 2002.

[18] H. Gunardson. Industrial Gases in Petrochemical Process- 1731 ing: Chemical Industries. Marcel Dekker, Inc, New York, NY, 1732 1998.

[19] B.C. Enger, R. Lødeng, and A. Holmen. A review of catalytic 1734 partial oxidation of methane to synthesis gas with emphasis 1735 on reaction mechanisms over transition metal catalysts. Appl. 1736 Catal. A, 346:1-27, 2008.

1737

[20] J.B. Claridge, M.L.H. Green, S.C. Tsang, A. York, A.T. 1738 Ashcroft, and P.D. Battle. A study of carbon deposition on 1739 catalysis during the partial oxidation of methane to synthesis 1740 gas. Catal. Lett., 22:299-305, 1993.

[21] J. Warnatz, M. D. Allendorf, R. J. Kee, and M. E. Coltrin. 1742 A model of elementary chemistry and fluid mechanics in the 1743 combustion of hydrogen on platinum surfaces. Combust. 1744 Flame, 96:393-406, 1994.

[22] L.D. Schmidt, O. Deutschmann, and Jr. C.T. Goralski. Mod- 1746 eling the partial oxidation of methane to syngas at millisecond 1747 contact times. Stud. Sur. Sci. Catal., 119:685-692, 1998.

[23] A.B. Mhadeshwar and D.G. Vlachos. Hierarchical, multiscale surface reaction mechanism development: $\mathrm{CO}$ and $\mathrm{H}_{2}$ oxidation, water-gas shift, and preferential oxidation of $\mathrm{CO}$ on $\mathrm{Rh}$. J. Catal., 234:48-63, 2005.

[24] E.S. Hecht, G.K. Gupta, H. Zhu, A.M. Dean, R.J. Kee, L. Maier, and O. Deutschmann. Methane reforming kinetics within a Ni-YSZ SOFC anode. Appl. Catal. A, 295:40-51, 2005.

[25] V.M. Janardhanan and O. Deutschmann. CFD analysis of a solid oxide fuel cell with internal reforming: Coupled interactions of transport, heterogeneous catalysis and electrochemical processes. J. Power Sources, 162:1192-1202, 2006.

[26] M. Maestri, D.G. Vlachos, A. Beretta, G. Groppi, and E. Tronconi. Steam and dry reforming of methane on Rh: Microkinetic analysis and hierarchy of kinetic models. J. Catal., 259:211222, 2008.

[27] L. Maier, B. Schaedel, K. Herrera Delgado, S. Tischer, and O. Deutschmann. Steam reforming of methane over nickel: Development of a multi-step surface reaction mechanism. Top. Catal, 54:845-858, 2011.

[28] O. Deutschmann. Modeling and Simulation of Heterogeneous Catalytic Reactions: From the Molecular Process to the Technical System. Wiley-VCH, Weinheim, Germany, 2012.

[29] S. Appari, V.M. Janardhanan, R. Bauri, S. Jayanti, and O. Deutschmann. A detailed kinetic model for biogas steam reforming on $\mathrm{Ni}$ and catalyst deactivation due to sulfur poisoning. Appl. Catal. A, 471:118-125, 2014.

[30] K. Herrera Delgado, L. Maier, S. Tischer, A. Zellner, H. Stotz, and O. Deutschmann. Surface reaction kinetics of steam and $\mathrm{CO}_{2}$-Reforming as well as oxidation of methane over nickelbased catalysts. Catalysts, 5:871-904, 2015.

[31] C. Karakaya, L. Maier, and O. Deutschmann. Surface reaction kinetics of the oxidation and reforming of $\mathrm{CH}_{4}$ over $\mathrm{Rh} / \mathrm{Al}_{2} \mathrm{O}_{3}$ catalysts. Int. J. Chem. Kinet., in press, 2016. DOI:10.1002/kin.20980.

[32] H. Zhu, R.J. Kee, V.M. Janardhanan, O. Deutschmann, and D.G. Goodwin. Modeling elementary heterogeneous chemistry and electrochemistry in solid-oxide fuel cells. J. Electrochem. Soc., 152:A2427-A2440, 2005.

[33] L. Maier, N. Schaedel, K.H. Delgado, S. Tisher, and O. Deutschmann. Steam reforming of methane over nickel: Development of a multi-step surface reaction mechanism. Top. Catal., 54:845-858, 2011.

[34] Y.-A. Zhu, D. Chen, X.-G. Zhou, and W.-K. Yuan. DFT studies of dry reforming of methane on Ni catalyst. Catal. Today, 148:260-267, 2009.

[35] J.M. Bray and W.F. Schneider. First-principles thermodynamic models in heterogeneous catalysis. In A. Asthagiri and M.J. Janik, editors, Computational Catalysis. The Royal Society of Chemistry, Cambridge, UK, 2012.

[36] P. Sautet F. Göltl. Density functional theory as a key approach in surface chemistry and heterogeneous catalysts. In J. Reedijk and K. Poeppelmeier, editors, Comprehensive Inorganic Chemistry II, volume 7, pages 405-420. Elsevier, Oxford, UK, 2 edition, 2013.

[37] A.B. Mhadeshwar and D.G. Vlachos. Hierarchical multiscale mechanism development for methane partial oxidation and reforming and for thermal decomposition of oxygenates on $\mathrm{Rh}$. J. Phys. Chem. B, 109:16819-16835, 2005.

[38] R.S. Vincent, R.P. Lindstedt, N.A. Malik, I.A.B. Reid, and B.E. Messenger. The chemistry of ethane dehydrogenation over a supported platinum catalyst. J. Catal., 260:37-64, 2008.

[39] C.F. Goldsmith. Estimating the thermochemistry of adsorbates based upon gas-phase properties. Topics in Catalysis, 55:366- 
$375,2012$.

[40] K.S. Wong, J.W. Thybaut, E.Tangstad, M.W. Stocker, and G.B. 1814 Marin. Methane aromatization based upon elementary steps: 1815 Kinetic and catalyst descriptors. Micropor. Mesopor. Mat., 1816 164:302-312, 2012.

[41] C. Karakaya, H. Zhu, and R.J. Kee. Kinetic modeling of 1818 methane dehydroaromatization chemistry on Mo/Zeolite cat- 1819 alysts in packed-bed reactors. Chem. Eng. Sci., 123:474-486, 1820 2015.

[42] M.E. Coltrin, R.J. Kee, and F.M. Rupley. Surface Chemkin: 1822 A generalized formalism and interface for analyzing heteroge- 1823 neous chemical kinetics at a gas-surface interface. Int. J. Chem. 1824 Kinet., 23:1111-1128, 1991. Flow. Wiley, Hoboken, NJ, 2003. face Chemkin-III: A fortran package for analyzing heteroge- 1829 neous chemical kinetics at a solid-surface - gas-phase inter- 1830 face. Technical Report SAND96-8217, Sandia National Labo- 1831 ratories, 1996.

[45] J.R. Rostrup-Nielsen and J. Sehested. Whisker carbon revis- 1833 ited. Stud. Surf. Sci. Catal., 139:1-12, 2001.

46] S. Helveg, J Sehested, and J.R. Rostrup-Nielsen. Whisker car- 183 bon in perspective. Catal. Today, 178:42-46, 2011.

[47] S. Helveg and P.L. Hansen. Atomic-scale studies of metal- 1837 lic nanocluster catalyst by in situ high-resolution transmission 1838 electron microscopy. Catal. Today, 111:68-73, 2006.

[48] K. Sasaki and Y. Teraoka. Equilibria in fuel cell gases. J. 1840 Electrochem. Soc., 150:A878-A888, 2003.

[49] M.D. Argyle and C.H. Bartholomew. Heterogeneous catalyst 1842 deactivation and regeneration: A review. Catalysts, 5:145-269, 1843 2015.

[50] L.L. Hegedus and R. W. McCabe. Catalyst poisoning. Stud. 1845 Surf. Sci. Catal., 6:481-505, 1980.

[51] C.H. Bartholomew. Mechanisms of nickel catalyst poisoning. 1847 Stud. Surf. Sci. Catal., 34:81-104, 1987.

[52] C. Hulteberg. Sulphur-tolerant catalysts in small-scale hydrogen production, a review. Int. J. Hydrogen Energ., 37:3978- 1850 3992, 2012.

[53] Y. Matsuzaki and I. Yasuda. The poisoning effect of sulfur- 1852 containing impurity gas on a SOFC anode: Part I. Dependence 1853 on temperature, time, and impurity concentration. Solid State 1854 Ionics, 132:261-269, 2000.

[54] G. Mancino, S. Cimino, and I. Lisi. Sulphur poi- 1856 soning of alumina supported Rh catalyst during dry re- 1857 forming of methane. Catal. Today, in press, 2015. 1858 DOI:10.1016/j.cattod.2015.10.035.

[55] W.S. Jablonski, S.M. Villano, and A.M. Dean. A comparison 1860 of $\mathrm{H}_{2} \mathrm{~S}, \mathrm{SO}_{2}$, and $\mathrm{COS}$ poisoning on $\mathrm{Ni} / \mathrm{YSZ}$ and $\mathrm{Ni} / \mathrm{K}_{2} \mathrm{O}-1861$ $\mathrm{CaAl}_{2} \mathrm{O}_{4}$ during methane steam and dry reforming. Appl. 1862 Catal. A, 502:399-409, 2015.

56] C. Xie, Y. Chen, Y. Li, X. Wang, and C. Song. Sulfur poisoning 1864 of $\mathrm{CeO}_{2}-\mathrm{Al}_{2} \mathrm{O}_{3}$-supported mono- and bi-metallic $\mathrm{Ni}$ and $\mathrm{Rh} 1865$ catalysts in steam reforming of liquid hydrocarbons at low and 1866 high temperatures. Appl. Catal. A, 390:210-218, 2010.

[57] D.A.J.M. Ligthart, J.A.Z. Pieterse, and E.J.M. Hensen. The 1868 role of promoters for Ni catalysts in low temperature (mem- 1869 brane) steam methane reforming. Appl. Catal. A, 405:108-119, 1870 2011.

[58] S.L. Lakhapatri and M.A. Abraham. Sulfur poisoning of Rh- 1872 $\mathrm{Ni}$ catalysts during steam reforming of sulfur-containing liquid 1873 fuels. Cata. Sci. Technol., 3:2755-2760, 2013.

[59] C. Yuan, N. Yao, X. Wang, J. Wang, D. Lv, and X. Li. The $\mathrm{SiO}_{2} 1875$ supported bimetallic Ni-Ru particles: A good sulfur-tolerant 1876 catalyst for methanation reaction. Chem. Eng. J., 260:1-10, 1877
2015.

[60] J.R. Rostrup-Nielsen. Sulfur-passivated nickel catalysts for carbon-free steam reforming of methane. J. Catal., 85:31-43, 1984.

[61] H-S. Roh, K.-W. Jun, and S.-E. Park. Methane-reforming reactions over $\mathrm{Ni} / \mathrm{Ce}-\mathrm{ZrO}_{2} / \theta-\mathrm{Al}_{2} \mathrm{O}_{3}$. Appl. Catal. A., 251:275-283, 2003

[62] S. Chenna, R. Banerjee, and P.A. Crozier. Atomic-scale observation of $\mathrm{Ni}$ activation process for partial oxidation of methane using in situ environmental TEM. ChemCatChem., 3:10511059, 2011.

[63] E.P.J. Mallens, J.H.B.J. Hoebink, and G.B. Marin. The reaction mechanism of the partial oxidation of methane to synthesis gas: A transient kinetic study over rhodium and a comparison with platinum. J. Catal., 167:43-56, 1997.

[64] T. Montini, A.M. Condó, N. Hickey, F.C. Lovey, L. De Rogatis, P. Fornasiero, and M. Graziani. Embedded Rh (1 wt.\%)@ $\mathrm{Al}_{2} \mathrm{O}_{3}$ : Effects of high temperature and prolonged aging under methane partial oxidation conditions. Appl. Catal. B, 73:84-97, 2007.

[65] T. Mony, J. Barbier Jr., and D. Duprez. Reactivity of steam in exhaust gas catalysts III. steam and oxygen/steam conversions of propane on a $\mathrm{Pd} / \mathrm{Al}_{2} \mathrm{O}_{3}$ catalyst. Appl. Catal. B, 9:251-266, 1996.

[66] S.E. Wanke and P.C. Flynn. The sintering of supported metal catalysts. Catal. Rev., 12:93-135, 1975.

[67] E. Ruckenstein and D.B. Dadyburjor. Sintering and redispersion in supported metal catalysts. Rev. Chem. Eng., 1983:251$356,1$.

[68] C.H. Bartholomew. Sintering kinetics of supported metals: New perspectives from a unifying GPLE treatment. Appl. Catal. A, 107:1-57, 1993.

[69] C. H. Bartholomew and R.J. Farrauto. Fundamentals of Industrial Catalytic Processes. Wiley, Hoboken, NJ, 2006.

[70] H.I. de Lasa, G. Dogu, and A. Ravella. Chemical reactor technology for environmentally safe reactors and products. Springer, New York, 1992.

[71] A.I. Stankiewicz and J.A. Moulijn. Process intensification: Transforming chemical engineering. Chem. Eng. Prog., 96:2234, 2000.

[72] M.F. Carolan, P.N. Dyer, M.A. Wilson, T.R. Ohrn, K.E. Kneidel, D. Peterson, C.M. Chen, and K.G. Rackets. Planar ceramic membrane assembly and oxidation reactor system. U.S. Patent 7,513,932, 2009.

[73] C.F. Miller, J. Chen, M.F. Carolan, and E.P. Foster. Advances in ion transport membrane technology for syngas production Catal. Today, 228:152-157, 2014.

[74] L.L. Anderson, P.A. Armstrong, R.R. Broekhuis, M.F. Carolan, J. Chen, M.D. Hutcheon, C.A. Lewinsohn, C.F. Miller, J.M. Repasky, D.M. Taylor, and C.M. Woods. Advances in ion transport membrane technology for oxygen and syngas production. Solid State Ionics, in press, 2015. DOI: http://dx.doi.org/10.1016/j.ssi.2015.11.010.

[75] R.C. Pattison and M. Baldea. Robust autothermal microchannel reactors. Comput. Chem. Eng., 81:171179, 2015.

[76] M. Ostadi, K. Dalane, E. Rytter, and M. Hillestad. Conceptual design of an autonomous once-through gas-to-liquid process - Comparison between fixed bed and microchannel reactors. Fuel Process. Technol., 139:186-195, 2015.

[77] D.M. Murphy, A. Manerbino, M. Parker, J. Blasi, R.J. Kee, and N.P. Sullivan. Methane steam reforming in a novel ceramic microchannel reactor. Int. J. Hydrogen Energy, 38:8741-8750, 2013.

[78] J.J. Lerou, A.L. Tonkovich, L. Silva, S. Perry, and J. McDaniel. Microchannel reactor architecture enables greener processes. 
Chem. Eng. Sci., 65:380-385, 2010.

[79] B. Blakeley and N.P. Sullivan. Fuel processing in a ceramic 1944 microchannel reactor: Expanding operating windows. Int. J. 1945 Hydrogen Energy, 41:3794-3802, 2016.

[80] R.K. Shah and D.P. Sekulić. Fundamentals of Heat Exchanger 1947 Design. Wiley, Hoboken, NJ, 2003.

[81] V. Hessel, A. Renken, J.C. Schouten, and J. Yoshida. Hand- 1949 book of Microreactors. Wiley VCH, Weinheim, Germany, 1950 2009.

[82] G. Tekautz, B. Zechner, L.E. Wiesegger, and D. Kirschneck. 1952 Principle and guidelines for selection of microstructured de- 1953 vices for mixing and reaction. In V. Hessel, A. Renken, J.C. 1954 Schouten, and J. Yoshida, editors, Handbook of Microreactors. 1955 Wiley VCH, Weinheim, Germany, 2009.

[83] I. Aartun, H.J. Venvik, A. Holmen, P. Pfiefer, O. Görke, and 1957 K. Schubert. Temperature profiles and residence time effects 1958 during catalytic partial oxidation and oxidative steam reform- 1959 ing of propane in metallic microchannel reactors. Catal. Today, 1960 110:98-107, 2005.

[84] Z. Anxionnaz, M. Cabassud, C. Gourdon, and P. Tochon. Heat 1962 exchanger/reactors (HEX reactors): Concepts, technologies: 1963 State-of-the-art. Chem. Eng. Process., 47:2029-2050, 2008. 1964

[85] R.J. Kee, B.B. Almand, J.M. Blasi, B.L. Rosen, M. Hart- 1965 mann, N.P. Sullivan, H. Zhu, A.R. Manerbino, S. Menzer, W.G. 1966 Coors, and J.L. Martin. The design, fabrication, and evaluation 1967 of a ceramic counter-flow microchannel heat exchanger. Appl. 1968 Therm. Eng., 31:2004-2012, 2011.

[86] J.W. Thybaut, G.B. Marin, C. Mirodatos, Y. Schuurman, A.C. 1970 van Veen, V.A. Sadykov, H. Pennemann, R. Bellinghausen, and 1971 L. Mleczko. A novel technology for natural gas conversion by 1972 means of integrated oxidative coupling and dry reforming of 1973 methane. Chem. Ing. Tech., 86:1588-1870, 2014.

[87] J.W. Hemmings, L. Bonnell, and E.T. Robinson. Method and 1975 apparatus for producing synthesis gas. U.S. Patent 76868561976 B2, 2010.

[88] S. Chakravarti, M.M. Shah, R.F. Drnevich, W.Y. Sarmiento- 1978 Darkin, B.r. Kromer, and S.M. Kelly. Method and system for 1979 producing methanol using oxygen transport membrane based 1980 reforming system. U.S. Patent 9115045 B2, 2015.

[89] S. Gupta, J.J. Adams, J.R. Wilson, E.G. Eddings, M.K. Maha- 1982 para, and P. Singh. Performance and post-test characterization 1983 of an OTM system in an experimental coal gasifier. Appl. En- 1984 ergy, 165:72-80, 2016.

[90] A. de Klerk and E. Furimsky. Catalysis in the Refining of 1986 Fischer-Tropsch Syncrude. Royal Society of Chemistry, Cam- 1987 bridge, England, 2010.

[91] S. Mousavi, A. Zamaniyan, M. Irani, and M. Rashidzadeh. 1989 Generalized kinetic model for iron and cobalt based Fischer- 1990 Tropsch synthesis catalysts: Review and model evaluation. 1991 Appl. Catal., A, 506:57-66, 2015.

[92] M.N. Yakubovich and P.E. Strizhak. Kinetic models of the 1993 molecular mass distribution of the products of the Fischer- 1994 Tropsch synthesis at cobalt catalysts. Theor. Exp. Chem., 1995 43:361-379, 2007.

[93] D. F ortsch, K. Pabst, and E. Groß-Hardt. The product dis- 1997 tribution in Fischer-Tropsch synthesis: An extension of the 1998 ASF model to describe common deviations. Chem. Eng. Sci., 1999 138:333-346, 2015.

[94] S.T. Sie and R. Krishna. Fundamentals and selection of ad- 2001 vanced Fischer-Tropsch reactors. Appl. Catal., A, 186:55-70, 2002 1999.

[95] G. Chabot, R. Guilet, P. Cognet, and C. Gourdon. A mathemat- 2004 ical modeling of catalytic milli-fixed bed reactor for Fischer- 2005 Tropsch synthesis: Influence of tube diameter on Fischer- 2006 Tropsch selectivity and thermal behavior. Chem. Eng. Sci., 2007
127:72-83, 2015.

[96] R. Krishna and S.T. Sie. Design and scale-up of the FischerTropsch bubble column slurry reactor. Fuel Process. Technol., 64:73-105, 2000.

[97] D.Y. Shin, K.S. Ha, M.J. Park, G. Kwak, Y.J. Lee, and K.W. Jun. CFD modeling of a modular reactor for the FischerTropsch synthesis: Effectiveness of a micro-scale cross-current cooling channel. Fuel, 158:826-834, 2015.

[98] S. Saeidi, M.K. Nikoo, A. Mirvakili, S. Bahrani, N.A.S. Amin, and M.R. Rahimpour. Recent advances in reactors for lowtemperature Fischer-Tropsch synthesis: Process intensification perspective. Rev. Chem. Eng., 31:209-238, 2015.

[99] S. Park, I. Jung, U. Lee, J. Na, K.S. Kshetrimayum, Y. Lee, C.J. Lee, and C. Han. Design and modeling of large-scale crosscurrent multichannel Fischer-Tropsch reactor using channel decomposition and cell-coupling method. Chem. Eng. Sci, 134:448-456, 2015.

[100] S. Park, I. Jung, Y. Lee, K.S. Kshetrimayum, J. Na, S. Park, S. Shin, D. Ha, Y. Lee, J. Chung, C. Lee, and C. Han. Design of microchannel Fischer-Tropsch reactor using cell-coupling method: Effect of flow configurations and distribution. Chem. Eng. Sci., 143:63-75, 2016.

[101] C. Karakaya and R.J. Kee. Progress in the direct catalytic conversion of methane to fuels and chemicals. Prog. Energy Combust. Sci., 55:60-97, 2016.

[102] G.E. Keller and M.M. Bhasin. Synthesis of ethylene via oxidative coupling of methane. J. Catal., 73:9-19, 1982.

[103] J.A. Labinger and K.C. Ott. Mechanistic studies on the oxidative coupling of methane. J. Phys. Chem., 91:2682-2684, 1987.

[104] H. Zanthoff and M. Baerns. Oxidative coupling of methane in the gas phase. Kinetic simulation and experimental verification. Ind. Eng. Chem. Res., 29:2-10, 1990.

[105] Q. Chen, J.H.B.J. Hoebink, and G.B. Marin. Kinetics of the oxidative coupling of methane at atmospheric pressure in the absence of catalyst. Ind. Eng. Chem. Res., 30:2088-2097, 1991.

[106] J.H.B.J. Hoebink, P.M. Couwenberg, and G.B. Marin. Fixed bed reactor design for gas-phase chain reactions catalyzed by solids: The oxidative coupling of methane. Chem. Eng. Sci, 49:5453-5463, 1994.

[107] J.H. Lunsford. The catalytic oxidative coupling of methane. Angew. Chem. Int. Ed, 34:970-980, 1995.

[108] Z. Stansch, L. Mleczko, and M. Baerns. Comprehensive kinetics of oxidative coupling of methane ove the $\mathrm{La}_{2} \mathrm{O}_{3} / \mathrm{CaO}$ catalyst. Ind. Eng. Chem. Res., 36:2568-2579, 1997.

[109] J. Sun, J.W. Thybaut, and G.B. Marin. Microkinetics of methane oxidative coupling. Catal. Today, 137:90-102, 2008.

[110] K. Tanakabe and E. Iglesia. Mechanistic aspects and reaction pathways for oxidative coupling of methane on $\mathrm{Mn} / \mathrm{Na}_{2} \mathrm{WO}_{4} / \mathrm{SiO}_{2}$ catalysts. J. Phys. Chem. C, 113:1013110145, 2009.

[111] D. Noon, A. Subsai, and S. Senkan. Oxidative coupling of methane by nanofiber catalysts. ChemCatChem, 5:146-149, 2013.

[112] H.R. Godini, S. Xiao, M. Kim, N. Holst, S. Jaso, O. Gorke, J. Steinbach, and G. Wozny. Experimental and model-based analysis of membrane reactor performance for methane oxidative coupling: Effect of radial heat and mass transfer. Ind. J. Eng. Chem., 20:1993-2002, 2014.

[113] B. Zohour, D. Noon, and S. Senkan. Spatial concentration and temperature profiles in dual-packed-bed catalytic reactors: Oxidative coupling of methane. ChemCatChem, 6:2815-2880, 2014.

[114] Z. Zhang, Z. Guo, and S. Ji. Numerical simulation of packedbed reactor for oxidative coupling of methane. J. Energy 
Chem., 24:23-30, 2015.

[115] N.Y. Usachev, V.V. Kharlamov, E.P. Belanova, and T.S. 2074 Starostina. Oxidative processing of light alkanes: State-of-the- 2075 art and prospects. Russ. J. Gen. Chem., 79:1252-1263, 2009. 2076

[116] U. Zavyalova, M. Holena, R. Schloegl, and M. Baerns. Sta- 2077 tistical analysis of past catalytic data on oxidative methane 2078 coupling for new insights into the composition of high- 2079 performance catalysts. ChemCatChem., 3:1935-1947, 2011. 2080

[117] C. Hammond, S. Conrad, and I. Hermans. Oxidative methane 2081 upgrading. ChemSusChem, 5:1668-1686, 2012.

[118] Evgenii V. Kondratenko, Michael Schlter, Manfred Baerns, 2083 David Linke, and Martin Holena. Developing catalytic ma- 2084 terials for the oxidative coupling of methane through statistical 2085 analysis of literature data. Catal. Sci. Technol., 5:1668-1677, 2086 2015.

[119] S.C. Reyes, E. Iglesia, and C.P. Kelkar. Kinetic-transport mod- 2088 els of bimodal reaction sequences-I. Homogeneous and het- 2089 erogeneous pathways in oxidative coupling of methane. Chem. 2090 Eng. Sci., 48:2643-2661, 1993.

[120] J.M. DeBoy and R.F. Hicks. Kinetics of the oxidative coupling 2092 of methane over 1 wt. \% Sr/La $\mathrm{La}_{3}$. J. Catal., 113:517-527, 2093 1988.

[121] R.P. Taylor and G.L. Schrader. Lanthanum catalysts for $\mathrm{CH}_{4}$ oxidative coupling-A comparison of theb reactivity of phases. 2096 Ind. Eng. Chem. Res., 30:1016-1023, 1991.

[122] Y. Feng, J. Niiranen, and D. Gutman. Kinetic studies of the 2098 catalytic oxidation of methane. 1. Methyl radical production 2099 on $1 \% \mathrm{Sr} / \mathrm{La}_{2} \mathrm{O}_{3}$. J. Phys. Chem., 95:6558-6563, 1991.

[123] M.T. Xu and J.H. Lunsford. Effect of temperature on methyl 2101 radical generation over $\mathrm{Sr} / \mathrm{La}_{2} \mathrm{O}_{3}$ catalysts. Catal. Lett., 2102 11:295-300, 1991.

2103

[124] T.L. Van, M. Che, J.M. Tatibouet, and M. Kermarec. Infrared 2104 study of formation and stability of $\mathrm{La}_{2} \mathrm{O}_{2} \mathrm{CO}_{3}$ during the ox- 2105 idative coupling of methane on $\mathrm{La}_{2} \mathrm{O}_{3}$. J. Catal., 142:18-26, 2106 1993.

[125] X. Fang, S. Li, J. Lin, J. Gu, and D. Yang. Production of $\mathrm{C}_{2} \mathrm{H}_{4} 2108$ through oxidative coupling of $\mathrm{CH}_{4}$ over W-Mn catalysts. J. 2109 Mol. Catal. (China), 6:427-433, 1992.

[126] H. Liu, X. Wang, D. Yang, R. Gao, Z. Wang, and J. Yang. 2111 Scale up and stability test for oxidative coupling of methane 2112 over $\mathrm{Na}_{2} \mathrm{WO}_{4}-\mathrm{Mn} / \mathrm{SiO}_{2}$ catalyst in a $200 \mathrm{~mL}$ fixed-bed reactor. 2113 J. Nat. Gas. Chem., 17:59-63, 2008.

[127] R. Koirala, R. Bchel, S.E. Pratsinis, and A. Baiker. Oxidative 2115 coupling of methane on flame-made $\mathrm{Mn}-\mathrm{Na}_{2} \mathrm{WO}_{4} / \mathrm{SiO}_{2}$ : In- 2116 fluence of catalyst composition and reaction conditions. Appl. 2117 Catal. A, 484:97-107, 2014

[128] T.W. Elkins and H.E. Hagelin-Weaver. Characterization of 2119 $\mathrm{Mn} / \mathrm{Na}_{2} \mathrm{WO}_{4} / \mathrm{SiO}_{2}$ and $\mathrm{Mn} / \mathrm{Na}_{2} \mathrm{WO}_{4} / \mathrm{MgO}$ catalysts for the ox- 2120 idative coupling of methane. Appl. Catal. A., 497:96-106, 2121 2015 .

[129] N. Hiyoshi and T. Ikeda. Oxidative coupling of methane over 2123 alkali chloride $\mathrm{MnNa}_{2} \mathrm{WO}_{4} / \mathrm{SiO}_{2}$ catalysts: Promoting effect 2124 of molten alkali chloride. Fuel Process. Technol., 133:29-34, 2125 2015.

[130] T. Ito, J.-X. Wang, C.-H. Lin, and J.H. Lunsford. Oxidative 2127 dimerization of methane over a lithium-promoted magnesium 2128 oxide catalyst. J. Am. Chem. Soc., 107:5062-5068, 1985.

[131] D.J. Driscoll, W. Martir, J.X. Wang, and J.H. Lunsford. For- 2130 mation of gas-phase methy radicals over MgO. J. Am. Chem. 2131 Soc., 107:58-63, 1985.

[132] P. Myrach, N. Nilius, S.V. Levchenko, A. Gonchar, T. Risse, 2133 K.-P. Dinse, L.A. Boatner, W. Frandsen, R. Horn, H.-J. Freund, 2134 R. Schlogl, and M. Scheffer. Temperature-dependent morphol- 2135 ogy, magnetic and optical properties of Li-doped MgO. Chem- 2136 CatChem, 2:854-862, 2010.
[133] S. Arndt, U. Simon, S. Heitz, A. Berthold, B. Beck, O. Goerke, J. D. Epping, T. Otremba, Y. Aksu, E. Irran, G. Laugel, M. Driess, H. Schubert, and R. Schomaecker. Li-doped MgO from different preparative routes for the oxidative coupling of methane. Top. Catal., 54:1266-1285, 2011.

[134] L. Tang, D. Yamaguchi, L. Wong, N. Burke, and Ken Chiang. The promoting effect of ceria on $\mathrm{Li} / \mathrm{MgO}$ catalysts for the oxidative coupling of methane. Catal. Today, 178:172-180, 2011.

[135] U. Simona, S. Arndt, T. Otremba, T. Schlingmann, O. Görke, K.-P. Dinsec, R. Schomäcker, and H. Schubert. Li/MgO with spin sensors as catalyst for the oxidative coupling of methane. Catal. Comm, 18:132-136, 2012.

[136] A. Vatani, E. Jabbari, M. Askarieh, and M. A. Torangi. Kinetic modeling of oxidative coupling of methane over $\mathrm{Li} / \mathrm{MgO}$ catalyst by genetic algorithm. J. Nat. Gas Sci. Eng, 20:347-356, 2014.

[137] V.R. Choudhary, S.A.R. Mulla, and V.H. Rane. Surface basicity and acidity of alkaline earth-promotted $\mathrm{La}_{2} \mathrm{O}_{3}$ catalysts and their performance in oxidative coupling of methane. J. Chem. Technol. Biotechnol., 72:125-130, 1998.

[138] S. Pak, P. Qui, and J.H. Lunsford. Elementary reactions in the oxidative coupling of methane over $\mathrm{Mn} / \mathrm{Na}_{2} \mathrm{WO}_{4} / \mathrm{SiO}_{2}$ and $\mathrm{Mn} / \mathrm{Na}_{2} \mathrm{WO}_{4} / \mathrm{MgO}$ catalysts. J. Catal., 179:222-230, 1998.

[139] S. Zarrinpashne, R. Ahmedi, and S. M. Zekordi. Catalytic direct converison of methane to ethane and ethlylene. U.S. Patent 7902113B2, 2011.

[140] B. Fallah and C. Falamaki. A new nano- $\left(2 \mathrm{Li}_{2} \mathrm{O} / \mathrm{MgO}\right)$ catalyst/porous alpha-alumina composite for the oxidative coupling of methane reaction. AIChE J., 56:717-728, 2010.

[141] P. Huang, Y. Zhao, J. Zhang, Y. Zhu, and Y. Sun. Exploiting shape effects of $\mathrm{La}_{2} \mathrm{O}_{3}$ nanocatalysts for oxidative coupling of methane reaction. Nanoscale, 5:10844-10848, 2013.

[142] J. Song, Y. Sun, R. Ba, S. Huang, Y. Zhao, J. Zhang, Y. Sun, and Y. Zhu. Monodisperse $\mathrm{Sr} / \mathrm{La}_{2} \mathrm{O}_{3}$ hybrid nanofibers for oxidative coupling of methane to synthesize $\mathrm{C}_{2}$ hydrocarbons. Nanoscale, 7:2260-2264, 2015.

[143] Y.H. Hou, W.C. Han, W.S. Xia, and H.L. Wan. Structure sensitivity of $\mathrm{La}_{2} \mathrm{O}_{2} \mathrm{CO}_{3}$ catalysts in the oxidative coupling of methane. ACS. Catal., 5:1663-1674, 2015.

[144] W.P. Schammel, J. Wolfennarger, M. Ajinkya, J. McCarty, J.M. Cizeron, S. Weinberger, J.D. Edwards, D. Sheridan, E.C. Scher, and J. McCormick. Oxidative coupling of methane systems and methods. U.S. Patent 2014/0107385 A1, 2014.

[145] A. Tkachenko, J. Gamoras, D. Karshtedt, G. Nyce, and F.R. Zurcher. Method for oxidative coupling of methane in the presence of nanowire catalyst. EP 2853521 A1, 2015.

[146] G.B. Skinner, A. Lifshitz, K. Scheller, and A. Burcat. Kinetics of methane oxidation. J. Chem. Phys., 56:3853-3861, 1972.

[147] J. Warnatz. Rate coefficients in the $\mathrm{C} / \mathrm{H} / \mathrm{O}$ system in combustion chemistry. Springer, Berlin, 1984.

[148] W. Tsang and R.F. Hampson. Chemical kinetic data base for combustion chemistry. Part I. Methane and related compounds. J. Phys. Chem. Ref. Data, 15:1087-1279, 1986.

[149] K.D. Champbell, H. Zhang, and J.H. Lunsford. Methane activation by the lanthanide oxides. J. Phys. Chem., 92:750-753, 1988.

[150] L. Luo ad X. Tang, W. Wang an Y. Wang, S. Sun, F. Qui, and W. Huang. Methyl radicals in oxidative coupling od methane directly confirmed by synchrotron VUV photoionization mass spectroscopy. Sci. Rep., 3:1625-1631, 2013.

[151] Q. Chen, P.M. Couwenberg, and G.B. Marin. Effect of pressure on the oxidative coupling of methane in the absence of catalyst. AlChE J., 40:521-535, 1994.

[152] H.R. Godini, S. Jaso, S. Xiao, H. Arellano-Garcia, M. Omid- 
khah, and G. Wozny. Methane oxidative coupling: Syntheis of 2203 membrane reactor networks. Ind. Eng. Chem. Res., 51:7747- 2204 $7761,2012$.

[153] N. Holst, S. Jaso, H.R. Godini, S. Gloser, H. Arellano-Garcia, 2206 G. Wozny, and J. Steinbach. Two-dimensional model for ox- 2207 idative coupling of methane in a packed-bed membrane reactor. 2208 Chem. Eng. Technol., 35:294-301, 2012.

[154] H.R. Godini, S. Xiao, M. Kim, N. Holst, S. Jaso, O. Gorke, 2210 J. Steinbach, and G. Wozny. Experimental and model-based 2211 analysis of membrane reactor performance for methane oxida- 2212 tive coupling: Effect of radial heat and mass transfer. Ind. J. 2213 Eng. Chem., 20:1993-2002, 2014.

[155] J.S. Ahari, S. Zarrinpashne, and M.T. Sadeghi. Micro-kinetic 2215 modeling of ocm reactions over $\mathrm{Mn} / \mathrm{Na}_{2} \mathrm{WO}_{4} / \mathrm{SiO}_{2}$ catalyst. 2216 Fuel Process. Technol., 115:79-87, 2013.

[156] B. Zohour, D. Noon, and S. Senkan. New insights into the ox- 2218 idative coupling of methane from spatially resolved concentra- 2219 tion and temperature profiles. ChemCatChem, 5:2809-2812, 2220 2013.

[157] R. Horn, K.A. Williams, N.J. Degenstein, and L.D. Schmidt. 2222 Syngas by catalytic partial oxidation of methane on rhodium: 2223 Mechanistic conclusions from spatially resolved measure- 2224 ments and numerical simulations. J. Catal., 242:92-102, 2006. 2225

[158] R. Horn, K.A. Williams, N.J. Degenstein, and L.D. Schmidt. 2226 Mechanism of $\mathrm{H}_{2}$ and $\mathrm{CO}$ formation in the catalytic partial 2227 oxidation of $\mathrm{CH}_{4}$ on $\mathrm{Rh}$ probed by steady-state spatial profiles 2228 and spatially resolved transients. Chem. Eng. Sci., 62:1298- 2229 1307, 2007.

[159] A. Donazzi, M. Maestri, B.C. Michael, A. Beretta, P. Forzatti, 2231 G. Groppi, E. Tronconi, L.D. Schmidt, and D.G. Vlachos. Mi- 2232 crokinetic modeling of spatially resolved autothermal $\mathrm{CH}_{4}$ cat- 2233 alytic partial oxidation experiments over Rh-coated foams. J. 2234 Catal., 275:270-279, 2010

[160] D. Schweer, L. Mleczko, and M. Baerns. OCM in a fixed-bed 2236 reactor: Limits and perspectives. Catal. Today, 21:357-369, 2237 1994.

[161] J.Y. Lee, W. Jeon, J.-W. Choi, Y.-W. Suh, J.-M. Ha, D.J. 2239 Suh, and Y.-K. Park. Scaled-up production of $\mathrm{C}_{2}$ hydrocar- 2240 bons by the oxidative coupling of methane over pelletized 2241 $\mathrm{Na}_{2} \mathrm{WO}_{4} / \mathrm{Mn} / \mathrm{SiO}_{2}$ catalysts: Observing hot spots for selective 2242 process. Fuel, 106:851-587, 2013.

[162] M.-S. Salehi, M. Askarishahi, H.R. Godini, O. Görke, and 2244 G. Wozny. Sustainable process design for oxidative cou- 2245 pling of methane (OCM): Comprehensive reactor engineer- 2246 ing via computational fluid dynamics (CFD) analysis of OCM 2247 packed-bed membrane reactors. Ind. Eng. Chem. Res., 2016. 2248 DOI:10.1021/acs.iecr.5b03292.

[163] K. Otsuka, S. Yokoyama, and A. Morikawa. catalytic activ- 2250 ity and selectivity control for oxidative coupling of methane 2251 by oxygen pumping through yttria stabilized zirconia. Chem. 2252 Lett., pages 319-322, 1985.

2253

[164] S.J. Xu and W.J. Thomson. Oxygen permeation rates through 2254 ion-conducting perovskite membranes. Chem. Eng. Sci., 2255 54:3839-3850, 1999.

[165] J. Hong, P. Kirchen, and A.F. Ghoniem. Numerical simulation 2257 of ion transport membrane reactors: Oxygen permeation and 2258 transport and fuel conversion. J. Membr. Sci., 407-408:71-85, 2259 2012.

[166] S.H. Lee, V.R. Manga, M.F. Carolan, and Z.-K. Liu. Defect 2261 chemistry and phase equilibria of $\left(\mathrm{La}_{1-x} \mathrm{Ca}_{x}\right) \mathrm{FeO}_{3-\delta}$ thermo- 2262 dynamic modeling. J. Electrochem. Soc., 160:F1103-F1108, 2263 2013.

[167] T.C. Geary and S.B. Adler. Oxygen nonstoichiometry and de- 2265 fect chemistry of the mixed conductor $\mathrm{La}_{0 .} \mathrm{Ca}_{0.1} \mathrm{FeO}_{3-\delta}$ at low 2266 oxygen partial pressure. Solid State Ionics, 253:88-93, 2013. 2267
[168] P. Kirchen, D.J. Apo, A. Hunt, and A.F. Ghoniem. A novel ion transport membrane reactor for fundamental investigations of the permeation and oxy-combustion under reactive flow conditions. Proc. Combust. Inst., 34:3463-3470, 2013.

[169] A. Hunt, G. Dimitrakopoulos, P. Kirchen, and A.F. Ghoniem. Measuring the oxygen profile and permeation flux across an ion transport $\mathrm{La}_{0.9} \mathrm{Ca}_{0.1} \mathrm{FeO}_{3-\delta}$ membrane and the development and validation of a multistep surface exchange model. J. Membr. Sci., 468:62-72, 2014.

[170] T. Schiestel, M. Kilgus, S. Peter, K.J. Caspary, H. Wang, and J. Caro. Hollow fiber perovskite membranes for oxygen separation. J. Membr. Sci., 258:1-4, 2005.

[171] X. Tan, Y. Liu, and K. Li. Mixed conducting ceramic hallowfiber membranes for air separation. AIChE J., 51:1991-2000, 2005.

[172] S. Liu and G.R. Gavalas. Oxygen selective ceramic hollow fiber membranes. J. Membr. Sci., 246:103-108, 2005.

[173] O. Czuprat, , T. Schiestel, H. Voss, and J. Caro. Oxidative coupling of methane in a BCFZ perovskite hollow fiber membrane reactor. Ind. Eng. Chem. Res., 49:10230-10236, 2010.

[174] N.H. Othman, Z. Wu, and K. Li. A micro-structured $\mathrm{La}_{0.6} \mathrm{Sr}_{0.4} \mathrm{Co}_{0.2} \mathrm{Fe}_{0.8} \mathrm{O}_{3-\delta}$ hollow fibre membrane reactor for oxidative coupling of methane. J. Membr. Sci., 468:31-41, 2014.

[175] N.H. Othman, Z. Wu, and K. Li. An oxygen permeable membrane microreactor with an in-situ deposited $\mathrm{Bi}_{1.5} \mathrm{Y}_{0.3} \mathrm{Sm}_{0.2} \mathrm{Fe}_{0.8} \mathrm{O}_{3-\delta}$ catalyst for oxidative coupling of methane. J. Membr. Sci., 488:182-193, 2015.

[176] J. Zhu, S. Guo, Z. Zhang, X. Jiang, Z. Liu, and W. Jin. $\mathrm{CO}_{2}$ tolerant mixed conducting multichannel hollow fiber membrane for efficient oxygen separation. J. Membr. Sci, 485:79-86, 2015.

[177] D. Lafarga, J. Santamaria, and M. Menendez. Methane oxidative coupling using porous ceramic membrane reactors-I. reactor development. Chem. Eng. Sci., 49:2005-2013, 1993.

[178] J. Coronas, J. Santamaria, and M. Menendez. Methane oxidative coupling using porous ceramic membrane reactors-II. reaction studies. Chem. Eng. Sci., 49:2015-2025, 1993.

[179] W. Kiatkittipong, T. Tagawa, S. Goto, S. Assabumrungra, K. Silpasup, and P. Praserthdam. Comparative study of oxidative coupling of methane modeling in various types of reactor. Chem. Eng. J., 115:63-71, 2005.

[180] H.R. Godini, H. Trivedi, A. Gili de Villasante, O. Gorke, S. Jaso, U. Simon, A. Berthold, W. Witt, and G. Wozny. Design and demonstration of an experimental membrane reactor set-up for oxidative coupling of methane. Chem. Eng. Res. Des., 91:2671-2681, 2013.

[181] H. Shirasaka, T. Shimonosono, Y. Hirata, and S. Sameshima. Analysis of gas permeability of porous alumina powder compacts. J. Asian Ceram. Soc., 1:368-373, 2013.

[182] S. Ishizuka. On the behavior of premixed flames in a rotating flow field: Eestablishment of tubular flames. Proc. Combust. Inst., 20:287-294, 1985.

[183] T. Takeno and S. Ishizuka. A tubular flame theory. Combust. Flame, 64:83-98, 1986.

[184] S. Ishizuka. Characteristics of tubular flames. Prog. Energy Combust. Sci., 19:187-226, 1993.

[185] S. Ishizuka, editor. Tubular Combustion. Momentum Press, New York, 2013.

[186] R.J. Kee, A.M. Colclasure, H. Zhu, and Y. Zhang. Modeling tangential injection into ideal tubular flames. Combust. Flame, 152:114-124, 2008.

[187] R. Schellen, L. Mleczko, E.H. Hoffmann, and S. Schubert. Method for oxidative coupling of methane and producing syngas. U.S. Patent 2011/0240926 A1, 2011. 
[188] J.M. Santamaria, E.E. Miro, and E.E. Wolf. Reactor simulation 2333 studies of methane oxidative coupling on a $\mathrm{Na} / \mathrm{NiTi0} 0_{3}$ catalyst. 2334 Ind. Eng. Chem. Res., 30:1157-1165, 1991.

[189] J. Santamaria M. Menéndez, J.A. Pen̆a, and J. Barahona. 2336 Methane oxidative coupling in fixed bed catalytic reactors with 2337 a distributed oxygen feed. A simulation study. Catal. Today, 2338 13:353-360, 1992.

[190] I.P. Androulakis and S.C. Reyes. Role of distributed oxy- 2340 gen addition and product removal in the oxidative coupling of 2341 methane. AIChE J., 45:860-868, 1999.

[191] S. Ramakrishnan and C.F. Edwards. Maximum-efficiency 2343 architectures for steady-flow combustion engines, II: Work- 2344 regenerative gas-turbine engines. Energy, 72:58-68, 2014. 2345

[192] T. Nada. Performance characterization of different configura- 2346 tions of gas turbine engines. Propul. Power Res., 3:121-132, 2347 2014.

[193] W.A. Sirignano, D. Dunn-Rankin, F. Liu, B. Colcord, and 2349 S. Puranam. Turbine burners: Performance improvement and 2350 challenge of flameholding. AIAA J., 50:1645-1669, 2012.

[194] U. Zavyalova, M. Geske, R. Horn, G. Weinberg, W. Frand- 2352 sen, M. Schuster, and R. Schlogl. Morphology and microstruc- 2353 ture of $\mathrm{Li} / \mathrm{MgO}$ catalysts for the oxidative coupling of methane. 2354 ChemCatchem, 3:949-959, 2011.

[195] S. Ma, X. Guo, L. Zhao, S. Scott, and X. Bao. Recent progress 2356 in methane dehydroaromatization: From laboratory curiosities 2357 to promising technology. J. Energy Chem., 22:1-20, $2013 . \quad 2358$

[196] P. Tang, Q. Zhu, Z. Wu, and D. Ma. Methane activation: The 2359 past and future. J. Energy Environ. Sci., 7:2580-2591, 2014. 2360

[197] R. Horn and R. Schlogl. Methane activation by heterogeneous 2361 catalysts. Catal. Lett., 145:23-29, 2015.

[198] L. Li, R. Borry, and E. Iglesia. Reaction-transport simula- 2363 tions of non-oxidative methane conversion with continuous hy- 2364 drogen removal - homogeneous-heterogeneous reaction path- 2365 ways. Chem. Engr. Sci., 56:1869-1881, 2001.

[199] W. Li, R.W. Borry, and E. Iglesia. Design and optimization of 2367 catalysts and membrane reactors for the non-oxidative conver- 2368 sion of methane. Chem. Eng. Sci., 57:4595-4604, 2002.

[200] Ø. Hatlevik, S.K. Gade, M.K. Keeling, P.M. Thoen, A.P. 2370 Davidson, and J.D. Way. Palladium and palladium alloy mem- 2371 branes for hydrogen separation and production: History, fab- 2372 rication strategies, and current performance. Sep. Purif. Tech- 2373 nol., 73:59-64, 2010.

[201] R.J. Kee, H. Zhu, B.W. Hildenbrand, E. Völlestad, M.D. 2375 Sanders, and R.P. O'Hayre. Modeling the steady-state and 2376 transient response or polarized and non-polarized proton- 2377 conducting doped-perovskite membranes. J. Electrochem. 2378 Soc., 160:F290-F300, 2013.

[202] E. Vøllestad, H. Zhu, and R.J. Kee. Interpretation of defect and gas-phase fluxes through mixed-conducting ceramics using Nernst-Planck-Poisson and integral formulations. J. Electrochem. Soc., 161:F114-F124, 2014.

[203] H. Zhu, S. Ricote, W.G. Coors, and R.J. Kee. Interpreting equilibrium-conductivity and conductivity-relaxation measurements to establish thermodynamic and transport properties for multiple charged defect conducting ceramics. Faraday Discuss., 182:49-74, 2015.

[204] H. Zhu and R.J. Kee. Membrane polarization in mixedconducting ceramic fuel cells and electrolyzers. Intl. J. Hydrogen Energy, 41:2931-2943, 2016.

[205] L. Devi, K.J. Ptasinski, and F.J.J.G. Janssen. Decomposition of naphthalene as a biomass tar over pretreated olivine: Effect of gas composition, kinetic approach, and reaction scheme. Ind. Eng. Chem. Res., 44:9096-9104, 2005.

[206] P. R. Buchireddy, R. M. Bricka, J. Rodriguez, and W. Holmes. Biomass gasification: Catalytic removal of tars over zeolites and nickel supported zeolites. Energy Fuels, 24:2707-2715, 2010.

[207] S.N. Paglieri and J.D. Way. Innovations in palladium membrane research. Separ. Purif. Method., 31:1-169, 2002.

[208] K.D. Kreuer. Proton-conducting oxides. Annu. Rev. Mater. Res., 33:333-359, 2003.

[209] T. Norby and Y. Larring. Mixed hydrogen ion-electronic conductors for hydrogen permeable membranes. Solid State Ionics, 136-137:139-148, 2000.

[210] Y. Liu, X. Tan, and K. Li. Mixed conducting ceramics for catalytic membrane processing. Catal. Rev. Sci. Eng., 48:145198, 2006.

[211] H. Matsumoto, T. Shimura, H. Iwahara, T. Higuchi, K. Yashiro, A. Kaimai, T. Kawada, and J. Mizusaki. Hydrogen separation using proton-conducting perovskites. J. Alloys Compd., 408412:456-462, 2006.

[212] B. Euser, J.R. Berger, H. Zhu, and R.J. Kee. Defect-transportinduced stress in mixed ionic-electronic conducting (MIEC) ceramic membranes. J. Electrochem. Soc., 163:F264-F271, 2016.

[213] K.J. Yoon, P.A. Zink, S. Gopalan, U.B. Pal, and L.R. Pederson. Defect chemistry and electrical properties of $\left(\mathrm{La}_{0.8} \mathrm{Ca}_{0.2}\right)_{0.95} \mathrm{FeO}_{3-\delta}$. J. Electrochem. Soc., 156:B795B800, 2009.

[214] A. Hunt, G. Dimitrakopoulos, and A.F. Ghoniem. Surface oxygen vacancy and oxygen permeation flux limits of perovskite ion transport membranes. J. Membr. Sci., 489:248-257, 2015.

[215] S.K. Kim, M.J. Shin, J. Rufner, K. van Benthem, J.H. Yu, and S. Kim. $\mathrm{Sr}_{0.95} \mathrm{Fe}_{0.5} \mathrm{Co}_{0.5} \mathrm{O}_{3-\delta}-\mathrm{Ce}_{0.9} \mathrm{Gd}_{0.1} \mathrm{O}_{2-\delta}$ dual-phase membrane: Oxygen permeability, phase stability, and chemical compatibility. J. Membr. Sci., 462:153-159, 2014.

[216] T. Zhu, Z. Yang, and M. Han. Dual-phase material and its potential application in oxygen transport membrane. J. Mater. Sci. Technol., 30:954-958, 2014.

[217] H. Cheng, L. Luo, W. Yao, X. Lu, X. Zou, and Z. Zhou. Novel cobalt-free $\mathrm{CO}_{2}$-tolerant dual-phase membranes of $\mathrm{Ce}_{0.8} \mathrm{Sm}_{0.2} \mathrm{O}_{2-\delta}-\mathrm{Ba}_{0.95} \mathrm{La}_{0.05} \mathrm{Fe}_{1-x} \mathrm{Zr}_{x} \mathrm{O}_{3-\delta}$ for oxygen separation. J. Membr. Sci., 492:220-229, 2015.

[218] A.S. Yu, T.-S. Oh, R. Zhu, A. Gallegos, R.J. Gorte, and J.M. Vohs. Surface modification of $\mathrm{La}_{0.8} \mathrm{Sr}_{0.2} \mathrm{CrO}_{3-\delta}$-YSZ dualphase membranes for syngas production. Faraday Discuss., 182:213-225, 2015.

[219] S.K. Kim, M.J. Shin, J. Rufner, K. van Benthem, J.H. Yu, and S. Kim. Highly stable dual-phase $\mathrm{Y}_{0.8} \mathrm{Ca}_{0.2} \mathrm{Cr}_{0.8} \mathrm{Co}_{0.2} \mathrm{O}_{3}$ $\mathrm{Sm}_{0.2} \mathrm{Ce}_{0.8} \mathrm{O}_{1.9}$ ceramic composite membrane for oxygen separation. J. Membr. Sci., 499:301-306, 2016. 